\title{
Physical and Mechanical Characterization of Fibrin-Based Bioprinted Constructs Containing Drug-Releasing Microspheres for Neural Tissue Engineering Applications
}

\author{
Ruchi Sharma ${ }^{1}$, Rebecca Kirsch ${ }^{1}$, Karolina Papera Valente ${ }^{1}$, Milena Restan Perez ${ }^{2}$ \\ and Stephanie Michelle Willerth $1,2,3,4,5, *$ (D)
}

\section{check for}

updates

Citation: Sharma, R.; Kirsch, R.; Valente, K.P.; Perez, M.R.; Willerth, S.M. Physical and Mechanical Characterization of Fibrin-Based Bioprinted Constructs Containing Drug-Releasing Microspheres for Neural Tissue Engineering Applications. Processes 2021, 9, 1205. https://doi.org/10.3390/pr9071205

Academic Editor: Shreyas

Kuddannaya

Received: 6 June 2021

Accepted: 9 July 2021

Published: 13 July 2021

Publisher's Note: MDPI stays neutral with regard to jurisdictional claims in published maps and institutional affiliations.

Copyright: (c) 2021 by the authors. Licensee MDPI, Basel, Switzerland. This article is an open access article distributed under the terms and conditions of the Creative Commons Attribution (CC BY) license (https:// creativecommons.org/licenses/by/ $4.0 /)$.
1 Department of Mechanical Engineering, University of Victoria, Victoria, BC V8W 2Y2, Canada; ruchis0983@gmail.com (R.S.); beckakirsch2@yahoo.co.uk (R.K.); kvalente@uvic.ca (K.P.V.)

2 Department of Biomedical Engineering, University of Victoria, Victoria, BC V8W 2Y2, Canada; milenarestan@hotmail.com

3 Division of Medical Sciences, University of Victoria, Victoria, BC V8W 2Y2, Canada

4 Centre for Biomedical Research, University of Victoria, Victoria, BC V8W 2Y2, Canada

School of Biomedical Engineering, University of British Columbia, Vancouver, BC V6T1Z3, Canada

Correspondence: willerth@uvic.ca; Tel.: +1-250-721-7303; Fax: +1-250-721-6051
Abstract: Three-dimensional bioprinting can fabricate precisely controlled 3D tissue constructs. This process uses bioinks-specially tailored materials that support the survival of incorporated cells-to produce tissue constructs. The properties of bioinks, such as stiffness and porosity, should mimic those found in desired tissues to support specialized cell types. Previous studies by our group validated soft substrates for neuronal cultures using neural cells derived from human-induced pluripotent stem cells (hiPSCs). It is important to confirm that these bioprinted tissues possess mechanical properties similar to native neural tissues. Here, we assessed the physical and mechanical properties of bioprinted constructs generated from our novel microsphere containing bioink. We measured the elastic moduli of bioprinted constructs with and without microspheres using a modified Hertz model. The storage and loss modulus, viscosity, and shear rates were also measured. Physical properties such as microstructure, porosity, swelling, and biodegradability were also analyzed. Our results showed that the elastic modulus of constructs with microspheres was $1032 \pm 59.7$ Pascal (Pa), and without microspheres was $728 \pm 47.6 \mathrm{~Pa}$. Mechanical strength and printability were significantly enhanced with the addition of microspheres. Thus, incorporating microspheres provides mechanical reinforcement, which indicates their suitability for future applications in neural tissue engineering.

Keywords: 3D bioprinting; neural tissues; rheology; indentation; elastic modulus

\section{Introduction}

Three-dimensional bioprinting uses cell-laden bioinks to fabricate tissue constructs, often in a layer-by-layer process [1,2]. The bioprinting system takes the details provided in a digital file to produce the shape and structure of the bioprinted constructs, which can be used for a variety of applications, such as drug screening and regenerative medicine $[3,4]$. The bioinks used should have high biocompatibility, slow degradability, and easily tunable mechanical properties [5]. A biocompatible bioink should result in high cell viability, proliferation, adhesion, migration, and differentiation into mature tissues [6]. The mechanical properties of the bioink play an important role in maintaining the desired tissue shape after bioprinting and influence the behavior of cells seeded inside the bioprinted construct [3,7-9]. Moreover, achieving the desired print resolution for the bioprinted construct depends on the rheological properties of bioinks [10-13]. Therefore, bioinks should possess appropriate rheological, mechanical, biocompatible, and biofunctional properties for the target tissue $[6,14]$. Other important properties that need to be considered when 
choosing bioinks include the material source (natural or synthetic) and required printing conditions [8,15].

Often, bioinks are produced from hydrogels, which have exceptionally high water retention abilities that allow for elasticity similar to native tissues [3,16-18]. The mechanical integrity and stability of engineered tissues depend upon the hydrogel-based bioinks used during fabrication. The adjustable concentration of biomaterials can appropriately tune the mechanical and rheological properties of hydrogels [19]. It is important to understand the effect of mechanical environment on neurite outgrowth for understanding neural tissue regeneration strategies. When Kayal et al. created physiologically relevant hydrogel substrates with controlled mechanical cues, the neural cell behavior could be analyzed by both the absolute substrate stiffness value and the underlying stiffness gradient [20]. Their results emphasize the importance of considering substrate stiffness in the development of neural tissue-engineered scaffolds [20]. Given that neural tissues have low mechanical stiffness-with Young's elastic moduli (E) in the order of 0.1 kilopascal (kPa)—compared to other tissues present in the body $[21,22]$, it is challenging to measure the mechanical properties using standard techniques, such as atomic force microscopy (AFM), impact indentation, and rheometry because these methods are indirect and require several assumptions that lead to variances in data across groups $[19,21,23-28]$. Such methods use mathematical modeling to correlate experimental measurements, such as displacement and load to stress and strain, to evaluate elastic modulus [19]. Alternatively, some researchers have directly measured the rheological properties of white and gray matter using indentation experiments on various regions of the brain, such as the midbrain, cerebrum, and thalamus $[29,30]$. They have demonstrated that simple indentation experiments require a much smaller portion of tissue compared to standard rheological tests. The indention method consistently produced robust measurements, which indicated that the white matter tissue was approximately one third stiffer than gray matter tissue. These studies validated the use of indentation methods to interpret the mechanical properties of neural tissues [19,21,23,26,29-33].

Previous studies suggested that stem cell differentiation is affected by the substrate's elasticity. Additionally, neural stem cells (NSCs) preferentially differentiate into the neural phenotype in soft substrates $(\sim 0.1-0.5 \mathrm{kPa})$, while glial phenotypes are predominant in stiffer substrates ( 1-10 kPa) [34-36]. Sundararaghavan et al. investigated the mechanical stiffness of neuronal scaffolds in a 3D collagen gel that contained a durotactic gradient. They found that seeded dorsal root ganglion cells responded to their environment by growing longer along the stiffness gradient [37]. Thus, the stiffness of the biomaterial should be tuned to match that of the native tissue to obtain applicable cell activity including cell differentiation, adhesion, proliferation, and migration [38]. Viscoelasticity-a material's elastic and viscous response to stress-is another important parameter to consider when working with bioinks. Living tissues have both elastic and viscous components, and the mechanical behavior of such materials is referred to as viscoelastic. Viscoelasticity can be measured by a rotational rheometer, which gives information about the storage $\left(\mathrm{G}^{\prime}\right)$ and loss modulus $\left(G^{\prime \prime}\right)$ [39]. $G^{\prime}$ refers to the ability of the hydrogel to store deformation energy in an elastic manner, which gives information about shape retention related to the extent of crosslinking. A higher degree of crosslinking results in a larger $G^{\prime} . G^{\prime \prime}$ represents the hydrogel's viscous flow and ability to dissipate energy $[40,41]$. When $G^{\prime \prime}$ is greater than $G^{\prime}$, the bioink exists in a liquid-like state, which assists its extrusion, but sacrifices print fidelity. When $G^{\prime}$ is greater than $G^{\prime \prime}$, the material assumes a more solid state, which is favorable for print fidelity but triggers nozzle clogging and nonuniform fibers. Hence, $G^{\prime}$ and $G^{\prime \prime}$ are important parameters for understanding the properties of the bioink and, accordingly, selecting a bioprinting modality [42].

Another key factor during the printing process is maintaining cell viability, which is influenced by the viscoelasticity and gelation of the bioink [11,41]. An increase in viscoelasticity and gelation increases shear stress, which can alter the differentiation of stem cells and cell signaling and cause cell death by disrupting membrane integrity $[4,6,43,44]$. The bioink's viscosity —resistance of a fluid to flow-also plays a significant role in cell viability. 
Low viscosity bioinks increase cell viability but often decrease the printed construct's fidelity [10], while bioinks with high viscosity have high structural fidelity but can result in more cell damage and death [45]. The bioink's viscosity can be modified by incorporating biological factors, drug-delivery carriers, nanomaterials, and combinations of biopolymers to improve their mechanical properties $[18,46]$. Furthermore, different bioprinters support different bioink viscosities. Efficient bioinks can allow the production of standardized printed constructs with controlled shapes and sizes. These bioinks should also facilitate printing with high fidelity and flexibility to acclimatize the flow and diffusion of nutrients as well as the movement of cells [47]. Additionally, swelling and degradation rates are other important properties of bioinks. An ideal bioink should degrade in a controlled way by creating space for new tissue $[17,48,49]$. Swelling is an intrinsic property of hydrogels as these gels expand due to solvent penetration into void spaces between the polymeric chain network. In the context of 3D bioprinting, the swelling degree also refers to a change in the dimensions of the bioprinted constructs [50-52]. The swelling ratio is an important parameter which controls the release patterns of drugs from these polymeric networks [52-54]. Research led by Daikuara et al. found the swelling ratio of bioink at $\mathrm{pH} 5(8.2 \% \pm 0.3)$ and $\mathrm{pH} 7.4(8.6 \% \pm 0.5)$. The swelling capacity of the printed construct was not affected by $\mathrm{pH}$ or the addition of platelet lysate, since platelet lysate and gelatin methacryloyl (GelMA) presented almost analogous swelling behaviors. GelMA is a semi-synthetic hydrogel that is similar to the extracellular matrix of native tissues and made up of gelatin derivatized with methacrylamide and methacrylate groups [55].

Another interesting study discussed the effect of liver decellularized extracellular matrix (dECM), which is an extracellular matrix of tissues from its native environment that has emerged as a biomaterial that preserves a tissue's native environment, promotes cell proliferation, and provides cues for cell differentiation [56]. When the liver dECM was added to GelMA, its swelling ratio notably increased. This research also found that the swelling ratio of GelMA with dECM hydrogel is about $932 \%$, which is much larger than that of GelMA hydrogel (about 644\%) [51]. Furthermore, porosity is also an important factor for bioprinted constructs since interconnected pores can facilitate better penetration and migration of cells $[3,22,57]$. Porous constructs are relevant since they enable the diffusion of nutrients and gases as well as the removal of metabolic waste $[50,57,58]$. Mansouri et al. synthesized 3D porous, graphene-polymer scaffolds that have improved stability in aqueous media and neuronal cell interactions using a reducing agent [57]. The stability of a 3D structure depends on the flow behavior of the hydrogel. Hydrogels mostly exhibit a non-Newtonian behavior where they have a nonlinear relationship between their shear stress and rate [42]. Hydrogels are mostly shear-thinning, meaning their viscosity decreases as shear rate increases $[40,42]$. The shear-thinning property of a bioink permits easy extrusion from the printing nozzle. Thixotropy is a time-dependent shear-thinning property that allows bioinks to return almost instantly to a gel state [42]. A fast gelation process also facilitates the deposition of layer-upon-layer while preserving the shape of the bioprinted construct for achieving a complex and high resolution structure. Hence, the optimal composition of the biomaterial should be chosen in consideration of its shearthinning properties $[3,4,47]$.

We have designed and validated our fibrin-based bioink incorporated with drugreleasing microspheres for creating functional neural tissues from hiPSC-derived NPCs in our previous works $[59,60]$. hiPSCs are especially relevant to neural tissue engineering since brain cells from patients are rarely available for research. hiPSC-derived neural tissues could become a powerful diagnostic and prognostic tool for drug screening [60-62]. Additionally, bioinks can efficiently mimic the extracellular matrix found in brain tissue. Our bioink has $20 \mathrm{mg} / \mathrm{mL}$ of fibrin $0.5 \% w / v$ of alginate $(120,000-190,000 \mathrm{~g} / \mathrm{mol}, \mathrm{M} / \mathrm{G}$ ratio 1.56), and $0.3 \mathrm{mg} / \mathrm{mL}$ of genipin, whereas the crosslinker has $20 \mathrm{mg} / \mathrm{mL}$ of calcium chloride, $0.075 \% w / v$ of Chitosan, and $1.7 \mathrm{U} / \mathrm{mL}$ of thrombin, all of which were purchased from Sigma, St. Louis, MO, United States. Fibrin, a blood-derived biomaterial, supports neural stem cell differentiation and has been widely used in bioinks. However, bioinks that 
only contain fibrinogen pass through the microfluidic print head too fast to be polymerized, even at the lowest pressure, due to low viscosity. $[19,62,63]$. To overcome this issue, the naturally derived materials alginate and chitosan were added to the bioink to increase its viscosity and gelation speed and, thus, the printability of the ink. Alginate and chitosan are also broadly used as bioink components $[8,62,64]$. The ionic potential differences cause an interaction between alginate and chitosan, in which a polyelectrolyte complex is formed through their interactions. These interactions produce a physically crosslinked film formed at the interface of these two materials. Moreover, alginate and fibrin do not interact with one another but, instead, form an interpenetrating network within the scaffold. Fibrin polymerized by thrombin and crosslinked calcium chloride tends to last one to two weeks in culture before being degraded by proteases released from incorporated cells. This degradation limits the usefulness of fibrin scaffolds for neural tissue engineering since it often requires more than two weeks of culture to achieve fully differentiated neural cell types. For the long-term stability of fibrin scaffolds, soluble protease inhibitors or additional chemical crosslinking can slow their degradation. Genipin, a naturally derived small molecule that originates from geniposide found in fruits, can be used to covalently crosslink protein amine groups in fibrin and chitosan, which thereby creates a multi-material scaffold. This crosslinking further stabilizes the hydrogel, but can also change the bioink's mechanical properties, mainly its stiffness and porosity. A study that considered the effect of genipin concentrations on hiPSC neural differentiation found that the elastic moduli of gels produced with genipin concentrations lower than $2.5 \mathrm{mM}$ were lower than gels produced without genipin. Additionally, pore size was also affected by genipin, with larger pores in gels made with genipin (1-5 mM) compared to those with no genipin added. Moreover, the porous structure of chitosan allowed cells and nutrients to diffuse and migrate through the structure and can be formed by crosslinking chitosan with a variety of agents $[8,18,62]$. However, to successfully engineer mature bioprinted tissues for drug testing, a bioink should be printed as a desired structure to maintain its integrity over the culture period to support cell growth and differentiation [13,40,42]. The bioink must also support cell-material interactions to promote cell attachment and migration and possibly deliver differentiation cues $[3,6,60,65]$. For printability, the bioink must be precisely tuned to the printing system with an appropriate viscosity and gelation time $[39,41,66,67]$. Furthermore, the printed structures must support the cells over their differentiation period to prevent premature degradation. Lastly, bioink should also be degradable yet retain enough mechanical properties for a sufficient time period to support tissue maturation $[49,53]$.

Microspheres (1-1000 $\mu \mathrm{m}$ in diameter) are drug-delivery particles that release drugs at a controlled rate to overcome localized drug-delivery issues and enhance the therapeutic efficacy of a drug $[52,59,60,68]$. Our previous work validated that microspheres provide a protective environment around the cells that reduces damage to cells while printing, which enhances cell viability post-printing; additionally, these bioprinted constructs containing microspheres provide an appropriate 3D microenvironment for cells to grow and differentiate [60]. Our group found that drug-releasing microspheres in bioprinted constructs enhanced neuronal differentiation by providing the localized and controlled delivery of morphogens over time. In contrast to procedures that require changing morphogencontaining media frequently, microspheres are a more cost-effective morphogen-delivery method $[59,60]$.

However, the physical and mechanical properties of these bioprinted neural tissues need to be assessed to determine if their properties are analogous to their corresponding native tissue. This study, in which we manually combined our novel microsphere-containing bioink and crosslinker as well as bioprinted constructs, characterizes the physical and mechanical properties of bioprinted constructs to provide insights into their properties in comparison to the bioink without additives. Here, we adapted two different mechanical characterization techniques to measure the viscoelastic properties of the bioprinted neural tissue comprised of fibrin-based bioink with and without microspheres $[4,19,21]$. Inter- 
estingly, many procedures have been used to measure the elastic moduli of soft hydrogel scaffolds since neurons need soft substrates to differentiate and mature. However, it is challenging to precisely measure the elastic moduli of soft substrates using conventional protocols $[4,19,35,64,69]$. Robinson et al. validated a direct method to acquire the elastic moduli of fibrin using a modified Hertz model for thin films. This method involves spherical indenters that are placed on top of the fibrin samples to create an indentation depth that is then correlated with elastic moduli [19]. The indentation method facilitates the elastic modulus of hydrogel samples to be evaluated by combining spherical indenters with fluorescence microscopy [19]. We performed indentation experiments on bioprinted constructs using specific spherical indenters and a modified Hertz model for thin films [19]. Later, we conducted parallel plate rheometry on bioprinted constructs and on manually combined bioink and crosslinker to quantify the frequency-dependent shear elastic moduli [21]. These techniques facilitated a better understanding of the mechanical characterization of bioprinted neural tissue. Lastly, we characterized the physical properties of our bioprinted constructs with and without microspheres, including their microstructure and porosity, since a porous structure improves cell viability, aggregation, and motility as well as biodegradability $[17,48-50,57,58]$. Moreover, we have performed these characterization techniques on bioprinted constructs and on manually combined bioink and crosslinker with and without microspheres.

\section{Materials and Methods}

\subsection{Fabrication of Drug Releasing Microspheres}

Microspheres were prepared using an oil-in-water $(o / w)$ emulsion process followed by the evaporation of the organic solvent as previously described [68]. For the water phase, 2\% PVA (polyvinyl alcohol (PVA) (Mw 13,000-23,000, 87-89\% hydrolyzed) (Sigma-Aldrich, St. Louis, MO, USA) solution was made by dissolving PVA in de-ionized water for $1 \mathrm{~h}$ at $85^{\circ} \mathrm{C}$ while mixing at a speed of $850 \mathrm{rpm}$ on a Corning PC-420D magnetic mixer. Later, $100 \mathrm{~mL}$ of $0.3 \%(w / v)$ PVA solution was made by diluting $2 \%$ PVA with de-ionized water and held at $35{ }^{\circ} \mathrm{C}$. Furthermore, $500 \mathrm{mg}$ of PCL was dissolved in $3 \mathrm{~mL}$ of DCM on a magnetic mixer for $15 \mathrm{~min}$ at $900 \mathrm{rpm}$ to produce the oil phase. Subsequently, $0.3 \mathrm{mg}$ of the drug (dissolved in $100 \%$ ethanol) was added to the oil phase to produce microspheres at a concentration of $0.6 \mu \mathrm{g} \mathrm{mg}^{-1}(w / w$, guggulsterone/PCL). After removing from the magnetic mixer, $3 \mathrm{~mL}$ of $2 \%$ PVA were slowly added to the oil solution to prevent disruption of the boundary layer. An emulsion of the solution $(w / o)$ was then produced by vortex mixing (Fisher Scientific, Waltham, MA, USA) at $3000 \mathrm{rpm}$ for $15 \mathrm{~s}$. This $(w / o)$ emulsion was immediately added to the $0.5 \%$ PVA water phase and held at $35{ }^{\circ} \mathrm{C}$ at a mixing speed of $500 \mathrm{rpm}$ for $4 \mathrm{~h}$ to achieve evaporation of the organic solvent. After mixing, the microspheres were isolated by centrifugation at $4000 \mathrm{rpm}$ (Eppendorf $5810 \mathrm{R}$ ) and washed with de-ionized water. For long-term storage, the microspheres were lyophilized for $24 \mathrm{~h}$ and stored at $-20{ }^{\circ} \mathrm{C}$. Lastly, the microspheres were sterilized by low power air-plasma treatment (Harrick Plasma, Ithaca, NY, USA) for $30 \mathrm{~s}$ before being added to our bioink.

\subsection{Derivation and Expansion of Neural Progenitor Cells (NPCs)}

hiPSC-derived NPCs were obtained from the hiPSCs (1-DL-01 line-male, WiCell Research Institute) as described previously [60]. Experiments (rheology and degradation) using hiPSC-derived NPCs were conducted with the approval of the University of Victoria's Human Ethics Committee under protocol number: 12-187. NPCs were cultured in STEMdiffTM Neural Progenitor Medium (NPM), (STEMCELLTM Technologies, Vancouver, BC, Canada) on cell culture plates coated with poly-L-ornithine (PLO, Sigma, St. Louis, MO, USA) and laminin (Sigma, St. Louis, MO, USA). The cultured NPCs were maintained at $37^{\circ} \mathrm{C}$ with $5 \% \mathrm{CO}_{2}$, and media change was performed on a daily basis. Once the cultures reached $80 \%$ confluence, the cells were cryopreserved in liquid nitrogen. 


\subsection{Bioprinting Tissue Constructs for Evaluation}

The bioink was prepared as previously described [62]. Constructs were bioprinted using Aspect's studio software (V1.2.59.0, Aspect Biosystems, Vancouver, BC, Canada) with and without microspheres using computer aided design [44] files as shown in Figure 1 for analyzing different physical and mechanical properties. Here, Figure 1a,c shows dome-shaped and Figure $1 \mathrm{~b}$,d shows disc-shaped CAD files. Furthermore, Figure 2a,b shows that bioink is depositing layer after layer on the platform to form the final structure. Microsphere-laden constructs ( $1 \% w / v$ microspheres in bioink) were printed with previously prepared microspheres. As shown in Figure 3a, a dome-shaped constructs with $\sim 10 \mathrm{~mm}$ diameter, $40 \%$ rectilinear infill, and 7 layers were bioprinted using the RX1 bioprinter (Aspect Biosystems, Vancouver, BC, Canada) for analyzing mechanical properties such as elastic modulus with indentation method as well as physical properties such as porosity, microstructure, and degradation process. Disc-shaped constructs in Figure $3 \mathrm{~b}$ with $\sim 30 \mathrm{~mm}$ diameter with $40 \%$ rectilinear infill were bioprinted using the RX1 bioprinter (Aspect Biosystems, Vancouver, BC, Canada) with 14 layers for measuring viscoelastic properties with an Anton Paar MCR 302 Rheometer (Anton Paar, Ostfildern-Scharnhausen, Germany). The size of the construct should match or be slightly wider than the diameter of the parallel plate $(25 \mathrm{~mm})$. Constructs were also bioprinted with varying densities of hiPSC-derived NPCs, such as 1, 2.5, and 5 million cells per $1 \mathrm{~mL}$ of bioink, to analyze viscoelastic properties. NPCs were mixed with bioink as in previously described protocols, and bioprinted constructs were fixed with paraformaldehyde before analyzing $[59,60,70]$. The printing speed was $25 \mathrm{~mm} / \mathrm{s}$, and channel pressures consisted of $60 \mathrm{mbar}$ for the bioink, 50 mbar for the crosslinker, and 100 mbar for buffer solution. After bioprinting, the constructs were gently transferred to 6- and 12-well culture plates with $2 \mathrm{~mL}$ of tris-buffered saline (TBS).

(a)

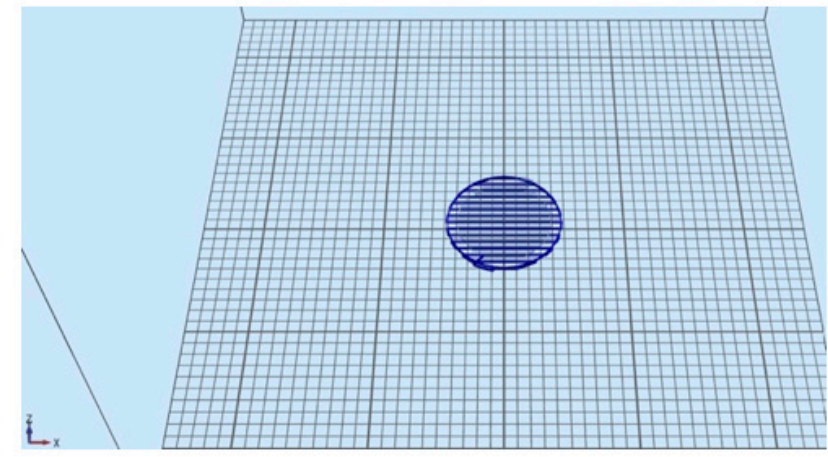

(c)

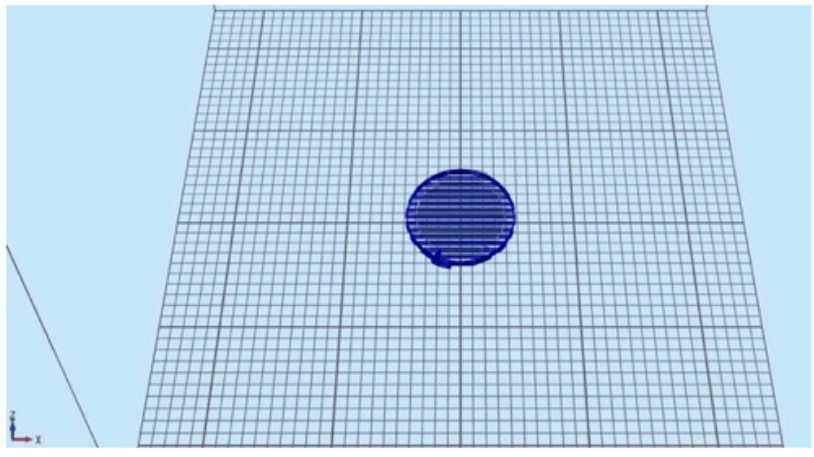

(b)

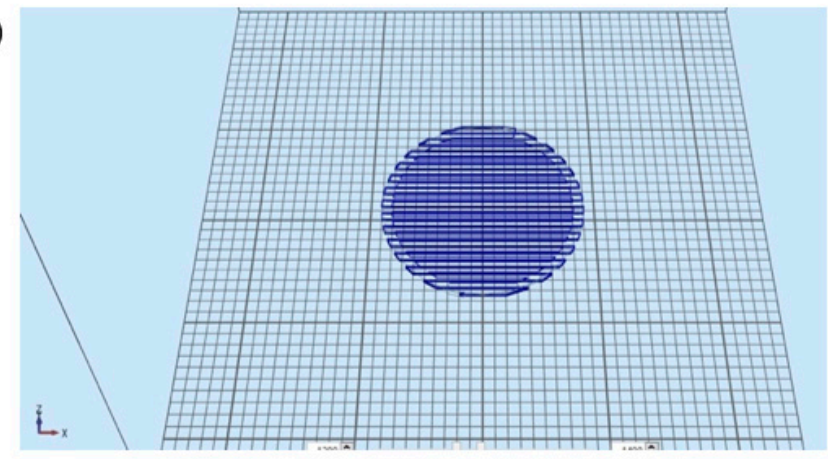

(d)

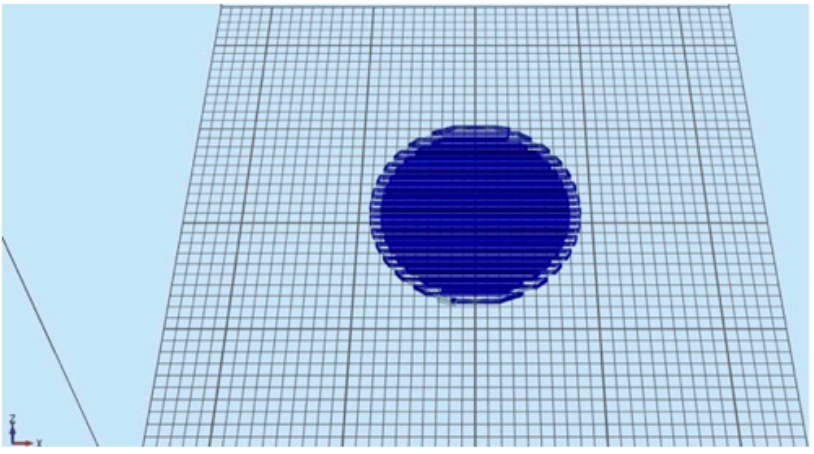

Figure 1. CAD file representing rectilinear infill pattern: $(\mathbf{a}, \mathbf{c})$ dome-shaped $(\sim 10 \mathrm{~mm}$ in diameter); (b,d) disc-shaped $(\sim 30 \mathrm{~mm}$ in diameter). 
(a)

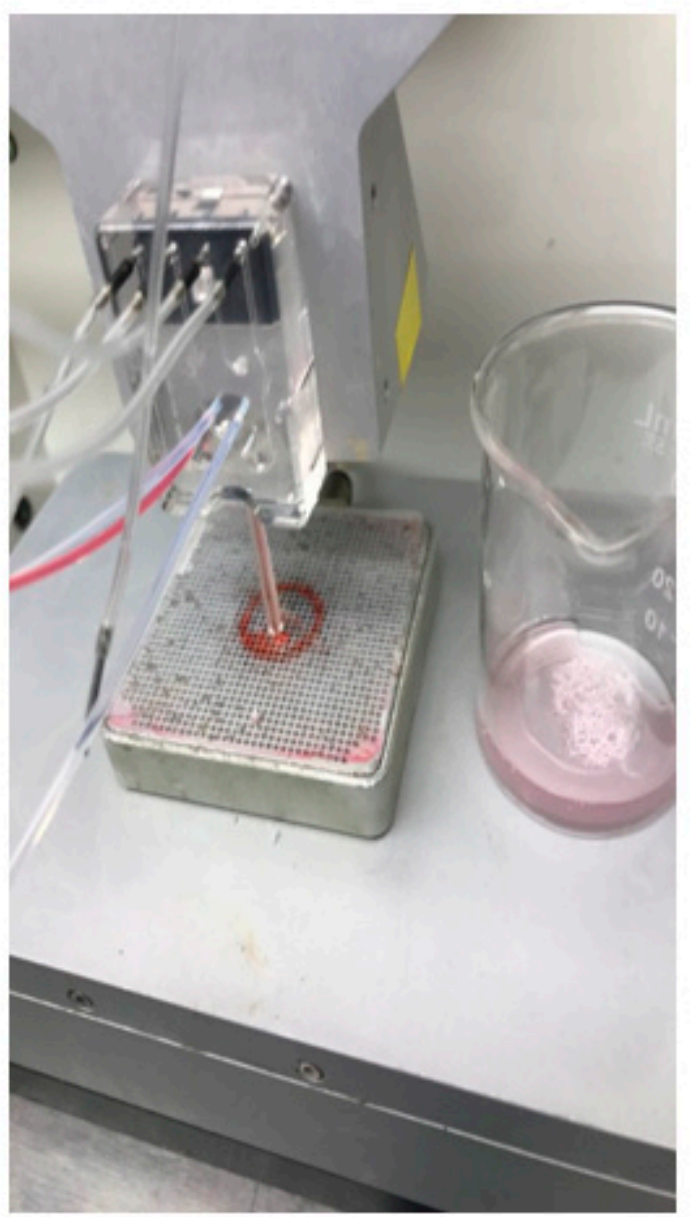

(b)

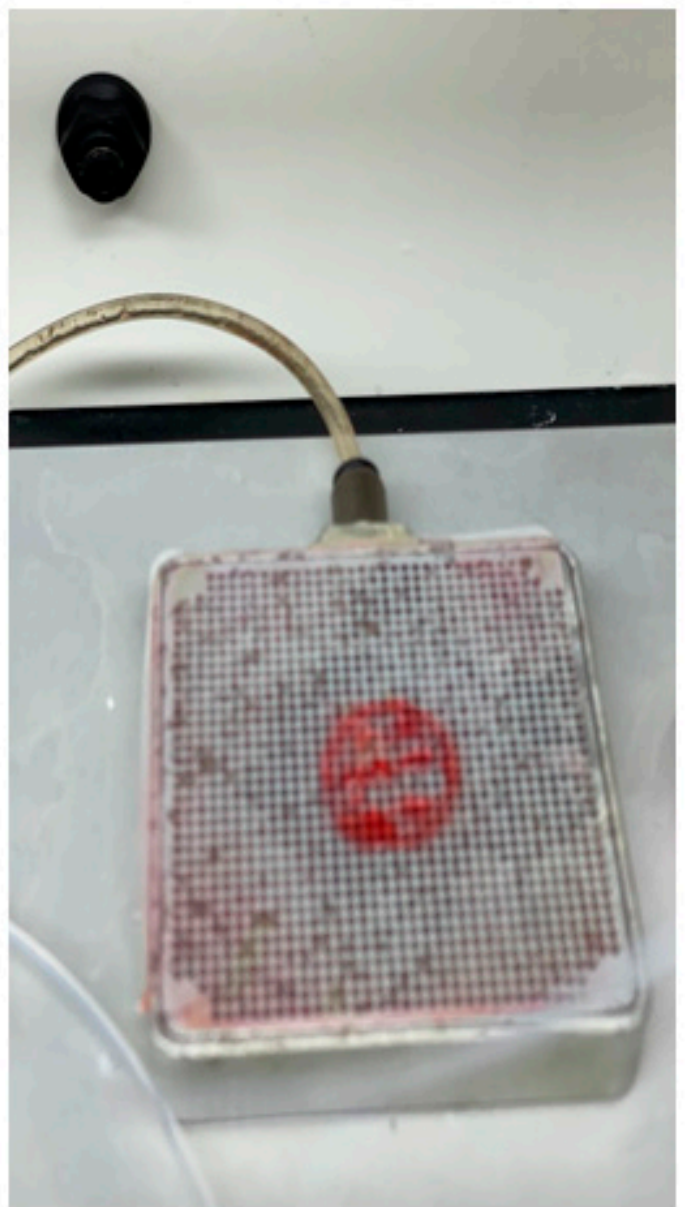

Figure 2. Bioprinted constructs consisting of fibrin-based bioink with phenol red (P3532, Sigma-Aldrich). (a) Aspect Biosystems duo-1 printhead printing a construct. (b) Bioprinted construct on nylon sheet placed on vacuum chuck showing first few layers of dome-shaped structure.

(a)

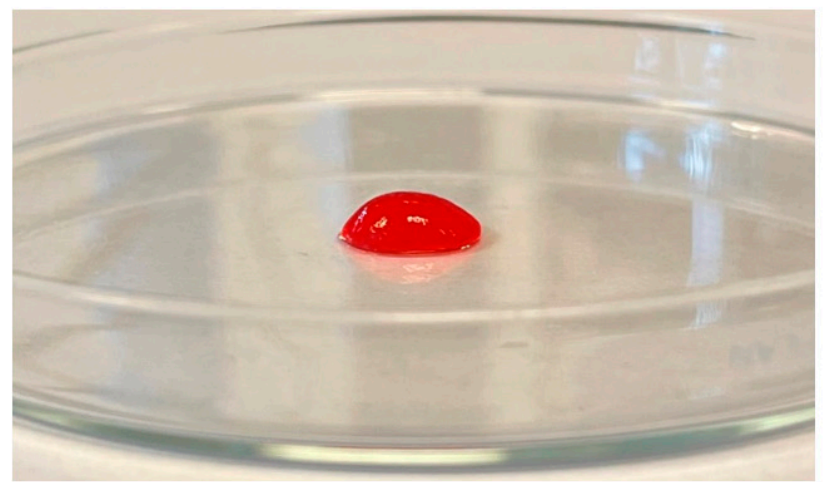

(b)

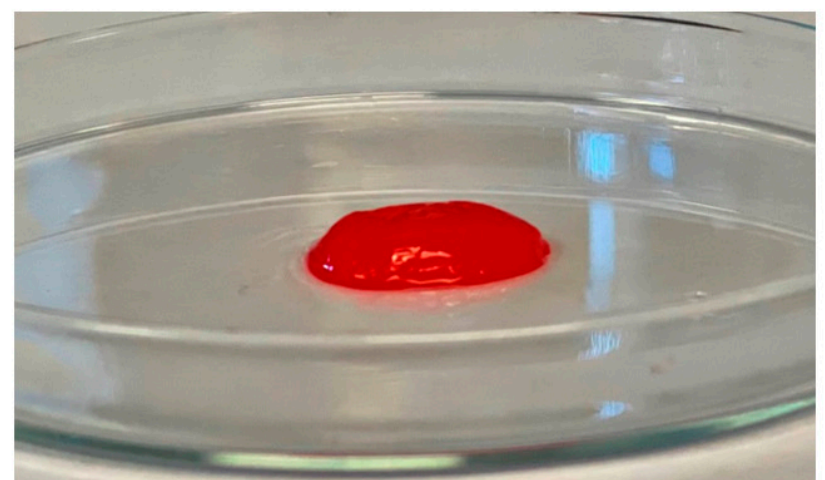

Figure 3. Bioprinted constructs of fibrin-based bioink with phenol red. (a) A dome-shaped ( 10 mm in diameter) construct within a glass Petri dish. (b) A disc-shaped ( $\sim 30 \mathrm{~mm}$ in diameter) construct within a glass Petri dish.

2.4. Mechanical Properties of Bioprinted Constructs as Well as Manually Combined Bioink and Crosslinker with and without Microspheres

\subsubsection{Indentation Method}

Elastic moduli of the bioprinted constructs were determined using the modified version of the indentation method for hydrogels [19,31,32,71,72]. Dome-shaped constructs were printed with fibrin-based bioink with and without microsphere and transferred to a 24-well plate. After the 3D printing process, the constructs were incubated with $3 \mathrm{~mL}$ 
of a $50 \mu \mathrm{M}$ fluorescein sodium salt solution prepared in a phosphate buffer solution (PBS) for $2 \mathrm{~h}$. This solution penetrated the constructs, fluorescently staining them. This staining allowed visualization of the construct under the laser scanning microscope (LSM 880 Zeiss). After incubation with fluorescein sodium salt, the 3D-printed constructs were rinsed three times with fresh PBS to remove the excess fluorescein dye. To clearly define the hydrogel surface during the imagining of the indentation process, $3 \mathrm{~mL}$ of a solution containing red fluorescent polystyrene particles in water was deposited in the wells of the constructs. The well plate was then moved to the sample stage of the LSM and left undisturbed for $1 \mathrm{~h}$ to allow deposition of the fluorescent particles on the hydrogel surface.

Two different types of spherical indenters were used during the measurements of elastic modulus. For the bioprinted constructs in absence of microspheres, a 3/16" zirconium dioxide indenter was carefully positioned on the surface of each sample, creating an indentation without permanent damage. For the constructs, which contained microspheres, a 3/16" stainless steel 302 indenter was used. After carefully positioning the indenter on the surface of the bioprinted samples, fluorescent images were acquired in the LSM. Images were obtained using a $10 \times$ objective lens (EC Plan-Neofluar $10 \times / 0.30 \mathrm{M} 27)$ and two excitation sources ( $488 \mathrm{~nm}$ and $543 \mathrm{~nm}$ ). A $488 \mathrm{~nm}$ argon laser was used to excite the fluorescein sodium salt molecules embedded in the samples, in which emission was collected from $500 \mathrm{~nm}$ to $550 \mathrm{~nm}$. A $543 \mathrm{~nm}$ helium-neon laser was used to excite red fluorescent polystyrene particles, with emission from $560 \mathrm{~nm}$ to $700 \mathrm{~nm}$. The indentation depth created by the indenter on the surface of the bioprinted constructs was measured by collecting Z-stack images with a layer height of $1 \mu \mathrm{m}$ and a refractive index of 1.33 . The indenter and samples were submerged in the water supernatant from the polystyrene solution. After collecting Z-stack images, cross-section images ( $X Z$ and $Y Z$ ) of the layers were obtained using the Zeiss Zen 2.3 software to measure the total height of the hydrogel samples and the deformation created at the surface of the samples by the indenter. All the indentation experiments and imaging were performed in triplicates and at room temperature $\left(25 \pm 2{ }^{\circ} \mathrm{C}\right)$.

As our group previously showed [19], the elastic moduli of the samples were obtained based on the modified Hertz model equation for thin films [48], by maintaining the indentation depth $(\delta)$, hydrogel thickness $(\mathrm{h})$, and indenter radius $(\mathrm{R})$ in the range of $\delta / \mathrm{h} \leq \mathrm{min}$ $(0.6, \mathrm{R} / \mathrm{h})$, and $0.3 \leq \mathrm{R} / \mathrm{h} \leq 12.7[73]$.

\subsubsection{Rheology with Rotational Rheometer (Anton Paar Rheometer)}

Testing was performed on bioprinted constructs with and without microspheres as well as on manually combined bioink (alginate, fibrin, and genipin) and crosslinker (chitosan, calcium chloride, and thrombin). Aspect Biosystems' RX1 bioprinting system employs a microfluidic print head to limit the harsh shear stress to cells as compared to conventional extruder-based printers, and this printhead requires chemically crosslinkable bioinks when printing. The crosslinker channel on the print head intersects with the bioink channel where it initiates gelation so the print head can extrude a continuous fiber. Here, the rheological tests were done on both bioink and crosslinker to understand the gelation as well as stiffness of crosslinked bioprinted constructs using a rheometer equipped with sandblasted parallel-plate fixtures (PP25/S, 3997) of diameter $25 \mathrm{~mm}$ with a gap width of 1 $\mathrm{mm}$ [74]. To determine the shear moduli of the bioink formulation, the bioink was loaded in its solution phase onto the plate $\left(25 \pm 2{ }^{\circ} \mathrm{C}\right)$, and the crosslinker solution was added on top of the bioink; then, the measuring plate was lowered into position. To determine the modulus of bioprinted constructs, approximately $30 \mathrm{~mm}$ diameter disc-shaped constructs were loaded on the rheometer. The frequency sweep was conducted from 0.1 to $100 \mathrm{rad} / \mathrm{s}$ at a $0.5 \%$ strain to measure frequency-dependent $G^{\prime}$ and $G^{\prime \prime}$. The viscosity was measured at shear rates from 0.01 to $90 \mathrm{~s}^{-1}$ to understand the deformation properties of a material. All the data were collected using Anton Paar Rheocompass software. 


\subsection{Microstructure of Bioprinted Constructs with and without Microspheres}

The microstructure of bioprinted constructs with and without microspheres was assessed by scanning electron microscopy (SEM, Hitachi S-4800) [50]. The bioprinted constructs were freeze-dried in a lyophilizer (VirTis Freezemobile 12EL $-85^{\circ} \mathrm{C}$ Freeze Dryer Lyophilizer w/16-Port Tree Manifold) for $24 \mathrm{~h}$ and cut into thin slices using a razor blade, then stored in their desiccated form at $-20{ }^{\circ} \mathrm{C}$ until analysis. SEM was used to characterize scaffolds, and the fact that it is a dry vacuum system means it cannot be used to examine wet specimens. Accordingly, bioprinted scaffolds were lyophilized before analysis, making the process of drying wet samples unavoidable, particularly for obtaining high resolution images. After lyophilization, samples were then sputter coated with gold-palladium (The Anatech Hummer VI, Au/Pd) before scanning. SEM analysis was done on three samples in three independent replicates for constructs with and without microspheres. The SEM images were captured using Hitachi S- 4800 software and diameters were measured using Quartz-PCI Image Management Systems ${ }^{\circledR}$ software (Quartz Systems, Vancouver, BC, Canada).

\subsection{Porosity of Bioprinted Constructs with and without Microspheres}

The bioprinted constructs were freeze-dried in a lyophilizer for $24 \mathrm{~h}$ prior to the porosity analysis. The porosity rate of bioprinted constructs with and without microspheres was calculated using Equation (1) as described previously [50]. V1 was defined as the initial volume of dehydrated alcohol used to submerge the freeze-dried bioink sample, V2 the total volume of the system when the sample was immersed in the dehydrated alcohol, and V3 the volume of the residual liquid after impregnating the sample. Three samples were recorded in three independent replicates for both microspheres and no microspheres groups.

$$
\text { Porosity }=(\mathrm{V} 1-\mathrm{V} 3) /(\mathrm{V} 2-\mathrm{V} 3) \times 100 \%
$$

\subsection{Swelling Ratio of Bioprinted Constructs with and without Microspheres}

The swelling ratio of bioprinted constructs with and without microspheres was measured by weighing the swollen and lyophilized bioprinted samples. The bioprinted samples were incubated in PBS at $37^{\circ} \mathrm{C}$ for $24 \mathrm{~h}$. Then, the samples were removed from the PBS, and the wet weight [75] of the samples was determined. Then, samples were lyophilized for $24 \mathrm{~h}$ and the dry weight $\left(\mathrm{W}_{\mathrm{d}}\right)$ was determined [51,55]. The swelling ratios of the hydrogels were calculated by Equation (2). Three samples were recorded in three independent replicates for both the microspheres and no microspheres groups.

$$
\text { Swelling ratio }=\left(\mathrm{W}_{\mathrm{s}}-\mathrm{W}_{\mathrm{d}}\right) / \mathrm{W}_{\mathrm{d}}
$$

\subsection{Biodegradation of Bioprinted Constructs with and without Microspheres}

The degradation rate in vitro of bioprinted constructs was detected by quantifying the decrease in weight. Briefly, freshly bioprinted construct samples were weighed (Wo) and incubated in NPC medium at $37^{\circ} \mathrm{C}$ for 14 days. At predetermined time points (t), bioprinted constructs were air dried and weighed $(\mathrm{Wt})$. The degradation rate of the construct was calculated by Equation (3) [50]. Three samples were recorded in three independent replicates for both the microspheres and no microspheres groups.

$$
\text { Degradation rate }=\left(\mathrm{W}_{\mathrm{O}}-\mathrm{W}_{\mathrm{t}}\right) / \mathrm{W}_{\mathrm{O}} \times 100 \%
$$

\subsection{Statistical Analysis}

All data were expressed as mean \pm standard deviation ( $n=3$ for all). Statistical analysis for the elastic modulus, porosity, and swelling ratio was carried out using an unpaired, two-tailed Student's t-test with 95\% confidence level. A one-way ANOVA analysis of variance with a Tukey post hoc analysis, with $95 \%$ confidence, was carried out 
for the degradation results. A value of $p<0.05$ was considered statistically significant. All statistical analysis was carried out using the GraphPad Prism 5 statistics software.

\section{Results}

3.1. Mechanical Properties of Bioprinted Constructs as Well as Manually Combined Bioink and Crosslinker with and without Microspheres

3.1.1. Measuring Elastic Modulus of Bioprinted Constructs with Indentation Method

The elastic modulus of the dome-shaped bioprinted constructs with a $1 \mathrm{~cm}$ diameter and $0.7 \mathrm{~cm}$ height was measured using the modified Hertz model for hydrogels [66]. As shown in Figure 4, hydrogel samples were fluorescently stained with green fluorescein sodium salt, while red fluorescent polystyrene particles were deposited on the surface of the samples. The indentation depth caused by the mass of the indenter was determined by $\mathrm{XZ}$ - and YZ-cross-section images of the constructs.

(a)

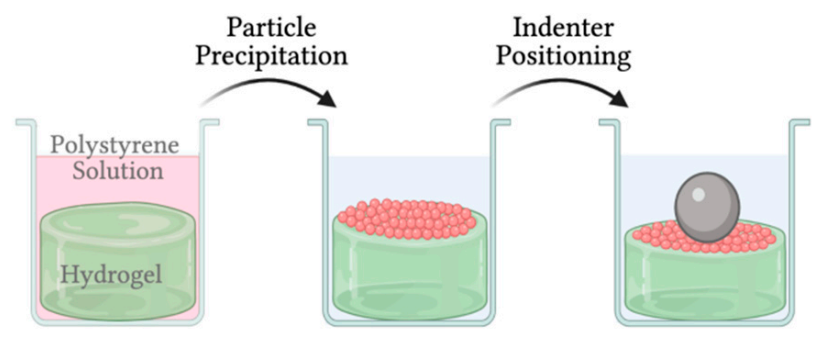

(b)

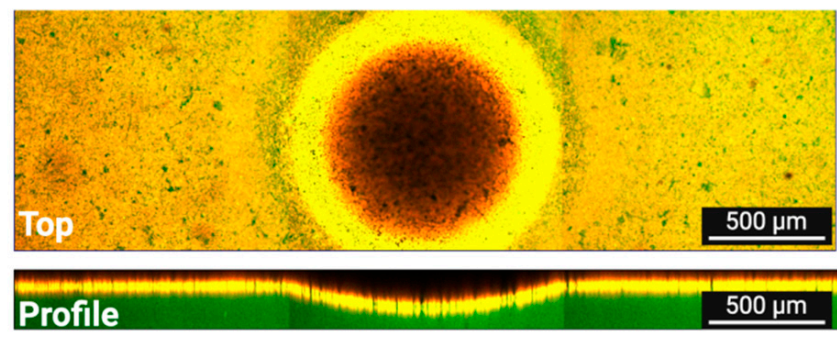

Figure 4. Setup for indentation experiment. (a) Bioprinted constructs were labeled with fluorescein sodium salt, while red polystyrene particles were deposited on its surface. Spherical ceramic indenters were positioned on the surface of the constructs, generating an indentation depth. (b) Indentation depths were measured by visualizing images obtained by the gel indented surface. Scale bar represents $500 \mu \mathrm{m}$.

Measurements of elastic moduli of the bioprinted constructs in absence of microspheres were performed using a $3 / 16^{\prime \prime}$ zirconium dioxide spherical indenter, with a density of $5.680 \mathrm{~g} / \mathrm{cm}^{3}$. For the 3D-printed samples with microspheres, the zirconium dioxide indenter was not sufficient to display a significant indentation depth on the surface of the hydrogels. In this case, a 3/16" stainless steel 302 spherical indenter with a density of $7.860 \mathrm{~g} / \mathrm{cm}^{3}$ was selected. The difference in the indenters is only in their material density. It is correct to compare results obtained with different indenters as long as the values obtained are in the range appropriate according to the modified Hertz model (Table 1). The bioprinted samples containing microspheres displayed higher stiffness values than without microspheres. The use of the $3 / 16^{\prime \prime}$ zirconium oxide indenter on the surface of the bioprinted samples with microspheres did not create a significant indentation depth that could be measured with confidence. Therefore, in order to create an indentation that could be measured in the confocal microscope, a heavier indenter was used (stainless steel 302). Considering that the result for the heavier indenter still obeys the limits of the modified Hertz model for thin films $(\delta / h \leq \min (0.6, R / h)$ and $0.3 \leq R / h \leq 12.7)$, Young's moduli values with different indenters can be compared. Table 1 displays the indentation parameters and elastic moduli values obtained for the 3D-printed samples. As expected, 
Figure 5 shows that the bioprinted constructs containing microspheres displayed a higher elastic modulus, which could be attributed to the incorporation of microspheres making it more mechanically and structurally stable. The incorporation of microspheres did not drastically increase the concentration of the bioink since the same printing pressures were used with the bioprinted constructs with and without microspheres. However, the increased concentration of microspheres greatly enhanced the stiffness of the bioprinted construct.

Table 1. Indentation parameters and elastic moduli values obtained for bioink with and without microspheres.

\begin{tabular}{ccc}
\hline Indentation Results & Without Microspheres & With Microspheres \\
\hline $0.3 \leq \mathrm{R} / \mathrm{h} \leq 12.7$ & $1.32 \pm 0.12$ & $1.43 \pm 0.17$ \\
$\delta / \mathrm{h} \leq \min (0.6, \mathrm{R} / \mathrm{h})$ & $0.33 \pm 0.02$ & $0.33 \pm 0.02$ \\
$\mathrm{E}_{\text {Hertz }}$ & $2025.9 \pm 170.7$ & $3096.8 \pm 356.3$ \\
$\mathrm{E}_{\text {modified Hertz }}$ & $728.4 \pm 47.6$ & $1032.6 \pm 59.8$ \\
\hline
\end{tabular}

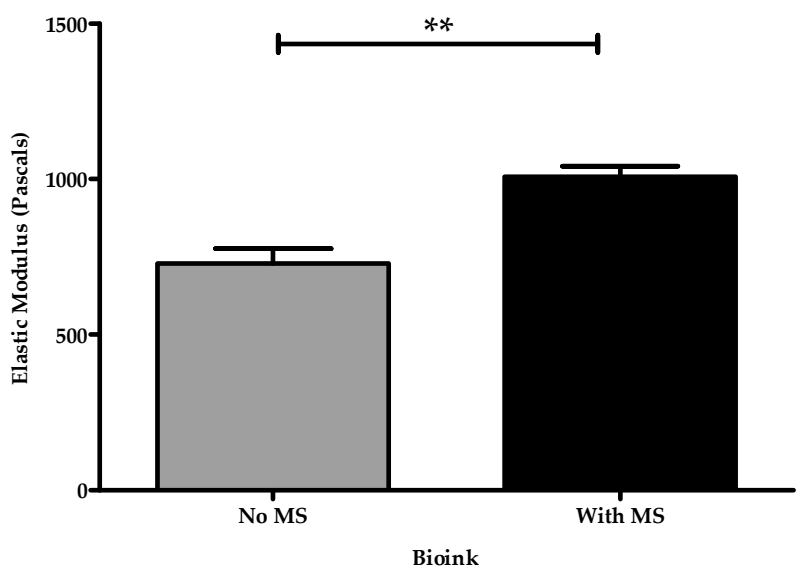

Figure 5. Elastic moduli values obtained from modified Hertz model for thin films. Data are presented as the average and standard deviation of three sample replicates. (MS: Microspheres). ** indicates that the elastic modulus are statistically different. $p<0.05$.

\subsubsection{Rheology with Rotational Rheometer (Anton Paar Rheometer)}

The viscosity and frequency sweep of the manually combined bioink and crosslinker solution with and without microspheres, as well as bioprinted constructs with cells and microspheres, were measured using an Anton Paar Rheometer [74]. The probability of extruding the hydrogel depends upon its viscosity. NPCs were printed in concentrations of $1,2.5$, and 5 million per $\mathrm{mL}$ of bioink to test the effects that these concentrations have on the mechanical strength of the bioprinted constructs. The viscosity was analyzed by regression analysis using the Carreau-Yasuda method with shear rate from 0.01 to $90 \mathrm{~s}^{-1}$. Figure $6 \mathrm{a}-\mathrm{c}$ shows that the viscosity depends on shear rate. The log of the shear rate and viscosity was taken to better understand the relationship between them. Here, the viscosity of $1,2.5$, and 5 million cells indicates that there is a decrease in viscosity with an increase of shear rate. Here, the viscosity measurement shows the shear-thinning property of the bioink. Shear thinning is important as it protects the cells during the printing process $[3,4]$.

$\mathrm{G}^{\prime}$ is associated with the elastic component of the viscoelastic behavior of a material or the more solid-state behavior of a material. In this study, the elastic component was tested on three different concentrations of cells in the bioink: 1, 2.5, and 5 million $/ \mathrm{mL}$. Figure $7 \mathrm{a}-\mathrm{c}$ shows that $\mathrm{G}^{\prime}$ increased when the angular frequency increased. At concentrations of 1 , 2.5 , and 5 million $/ \mathrm{mL}, \mathrm{G}^{\prime}$ was represented in logarithmic scale to better understand the relation between storage and loss modulus with angular frequency. Hence, the addition of cells resulted in an increase in $\mathrm{G}^{\prime}$. 
(a)

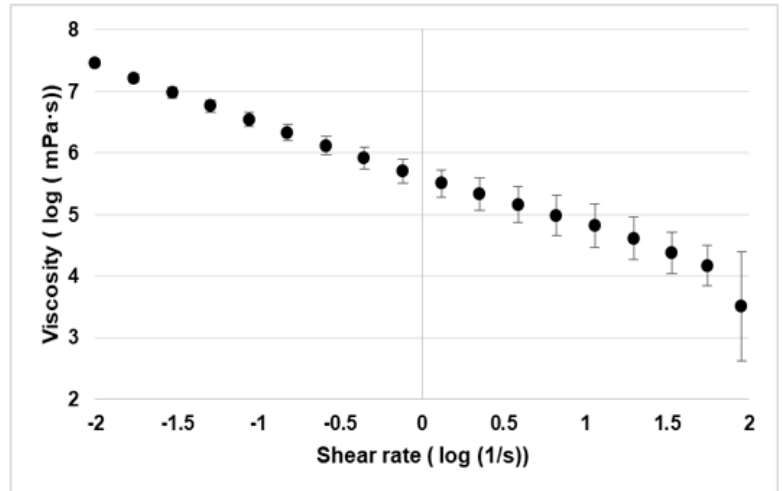

(b)

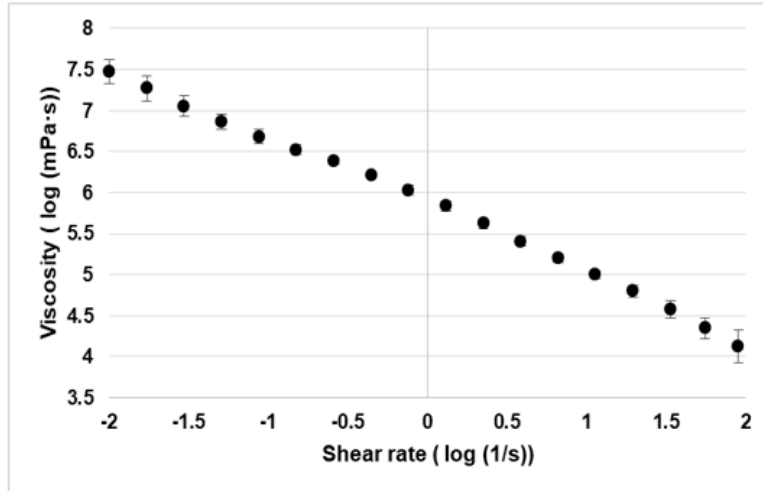

(c)

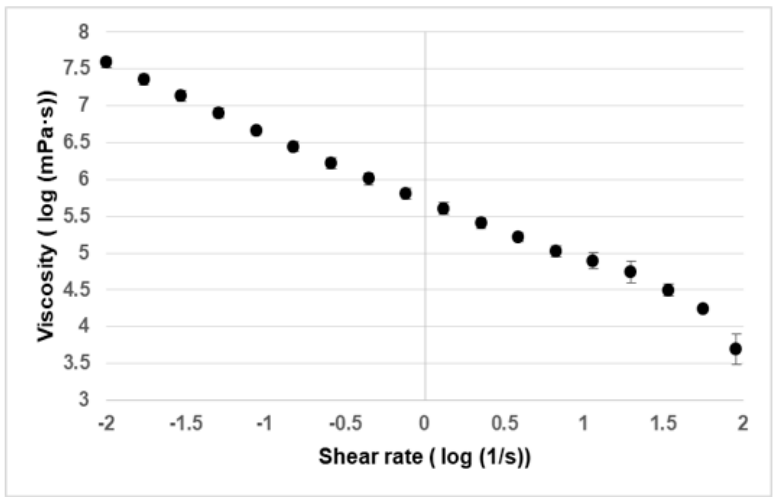

Figure 6. Rheological properties. (a) Viscosity/shear rate curve of bioprinted constructs with 1 million NPCs and microspheres. (b) Viscosity/shear rate curve of bioprinted constructs with 2.5 million NPCs and microspheres. (c) Viscosity/shear rate curve of bioprinted constructs with 5 million NPCs and microspheres.

(a)

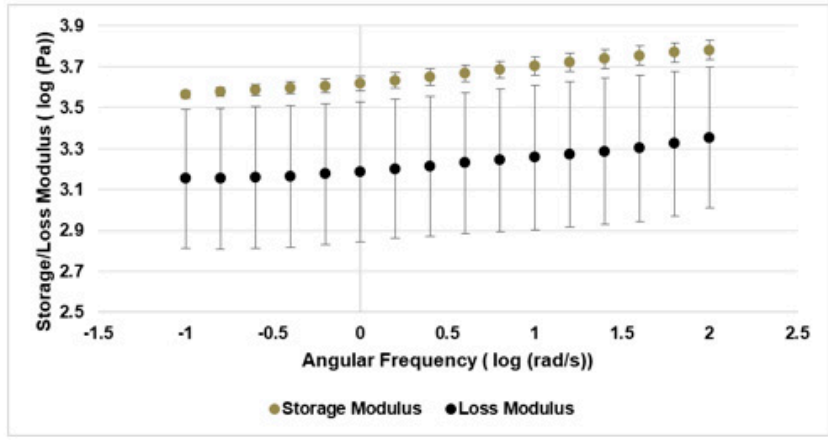

(b)

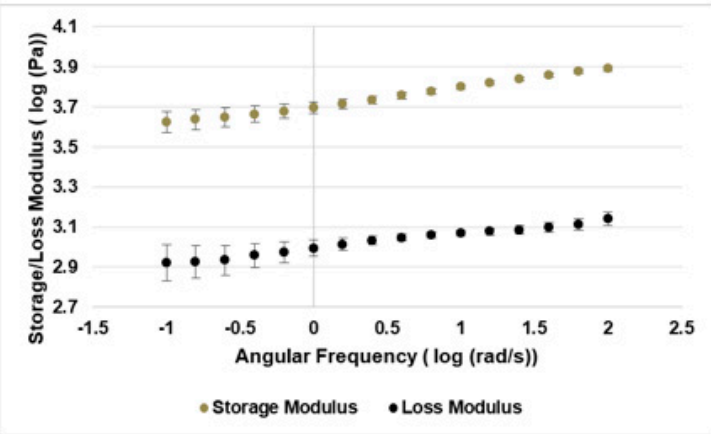

(c)

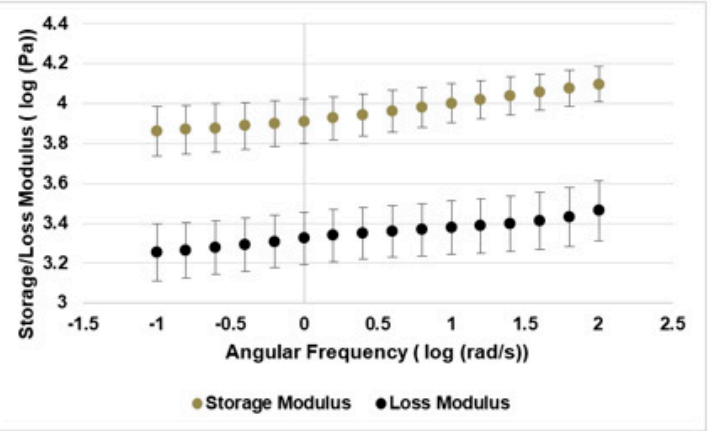

Figure 7. Rheological properties. (a) Storage/loss modulus of bioprinted constructs with 1 million cells and microspheres. (b) Storage/loss modulus of bioprinted constructs with 2.5 million cells and microspheres. (c) Storage/loss modulus of bioprinted constructs with 5 million cells and microspheres. 
Figure 8a shows that the viscosity of the bioprinted constructs with and without microspheres decreases while the shear rates increase. Similarly, Figure 8b representing the viscosity of the manually combined bioink and crosslinker with and without microspheres showed that the viscosity increased with shear rate. Figure $9 a, b$ shows that $G^{\prime}$ increases with angular frequency in bioprinted constructs; however, $\mathrm{G}^{\prime \prime}$ slightly increases as compared to $G^{\prime}$. Figure $9 \mathrm{c}$,d shows a slight difference as bioink and crosslinker with microspheres take slightly longer to crosslink on the rheometer's platform as compared to bioink and crosslinker without microspheres. The overall increase in $\mathrm{G}^{\prime}$ indicates that the elastic behavior becomes more dominant. However, $G^{\prime \prime}$ is a more liquid-like property. If $G^{\prime \prime}$ is greater than $\mathrm{G}^{\prime}$, then the applied mechanical force overtakes the interparticle forces, and the material starts to flow [76,77].

(a)

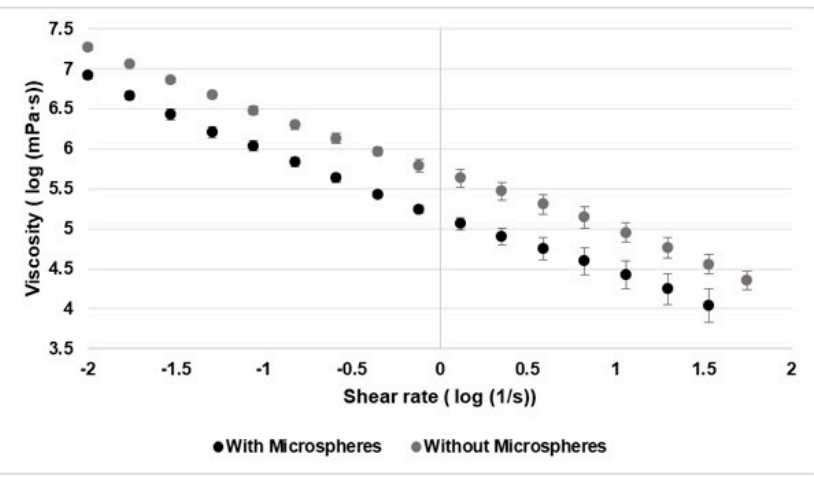

(b)

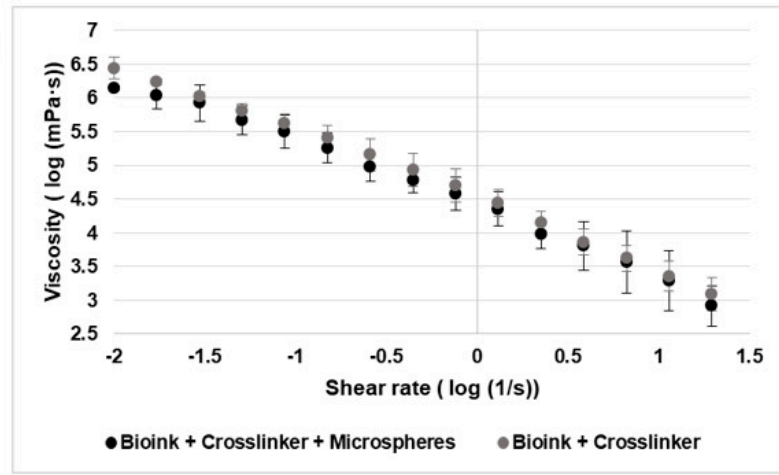

Figure 8. Rheological properties. (a) Viscosity/shear rate curve of bioprinted constructs with and without microspheres. (b) Viscosity/shear rate curve of manually combined bioink and crosslinker printed constructs with and without microspheres.

(a)

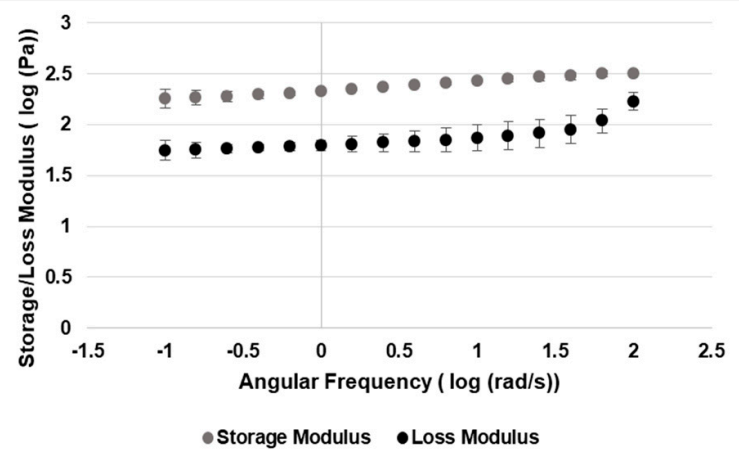

(c)

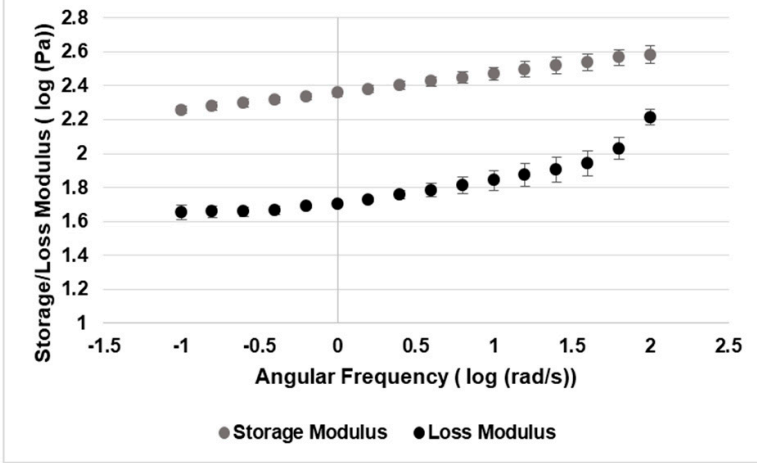

(b)

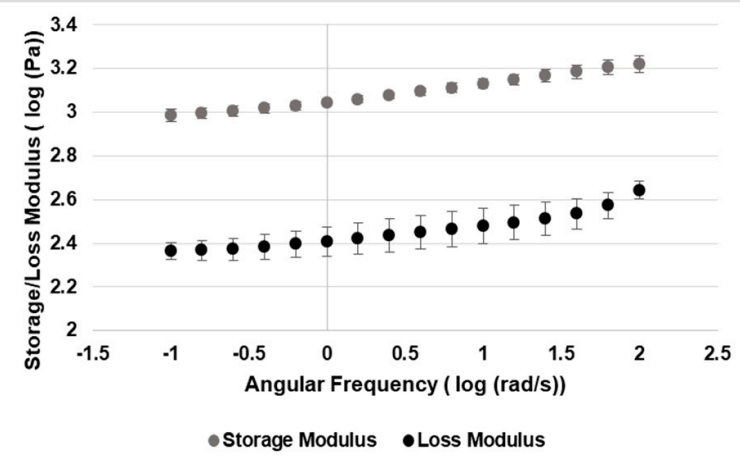

(d)

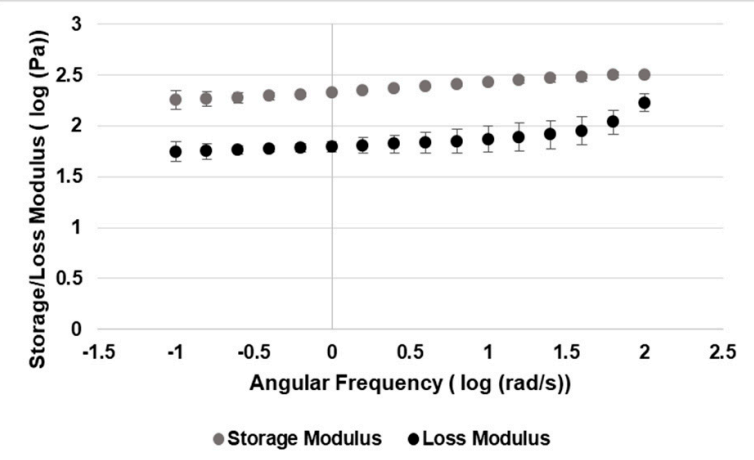

Figure 9. Rheological properties. (a) Storage and loss modulus of bioprinted constructs with microspheres. (b) Storage and loss modulus of bioprinted constructs without microspheres. (c) Storage and loss modulus of manually combined bioink and crosslinker. (d) Storage and loss modulus of manually combined bioink and crosslinker with microspheres. 


\subsection{Microstructure of Bioprinted Constructs with and without Microspheres}

Freeze-dried constructs were characterized using SEM to investigate the microstructure and the distribution of microspheres. Figure 10a-h shows the 3D homogenous, macroporous structure with interconnected porosity observed in both groups with the pore sizes ranging from 0.11 to $0.31 \mathrm{um}$. Figure $10 \mathrm{e}-\mathrm{h}$ shows that microspheres were uniformly distributed in the porous structure. These microspheres were smaller in size (1-10 um) and were found to be uniformly distributed in the porous structure.

(a)

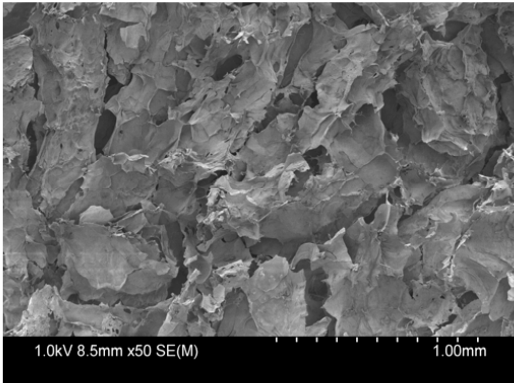

(c)

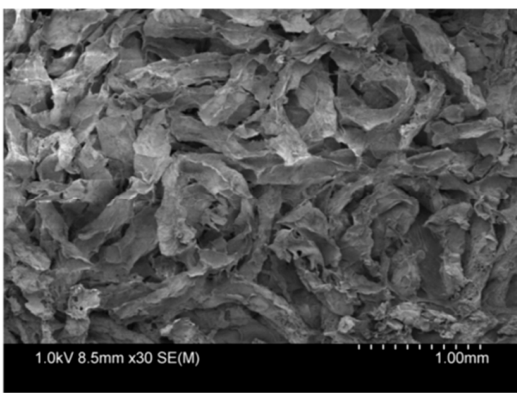

(b)

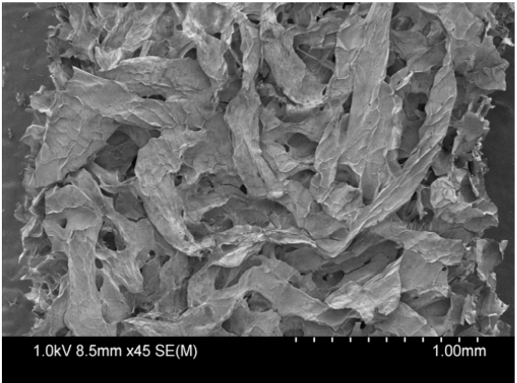

(d)

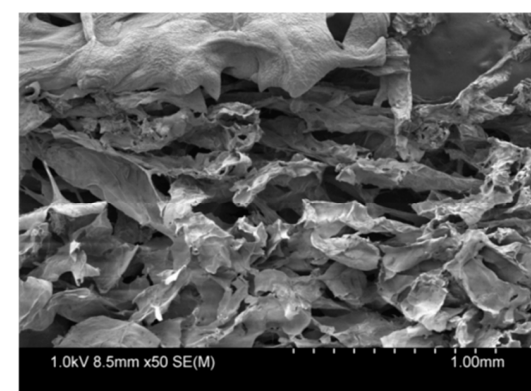

(e)

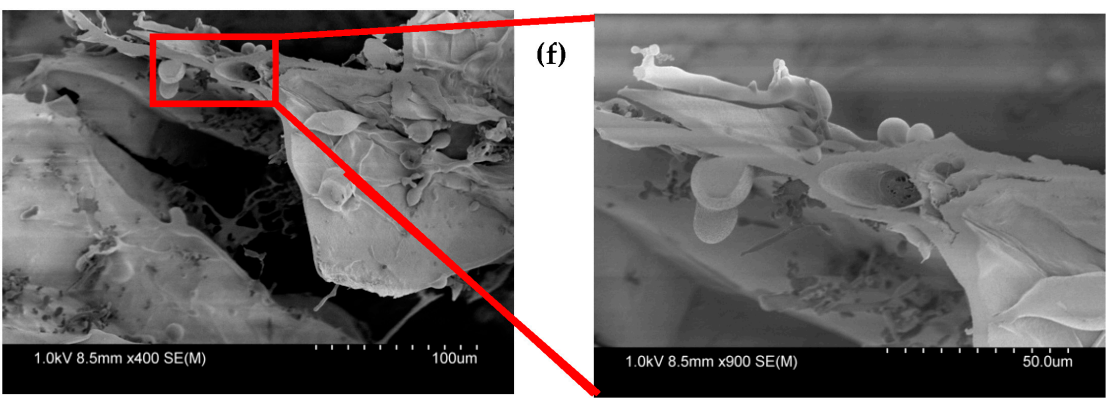

(g)

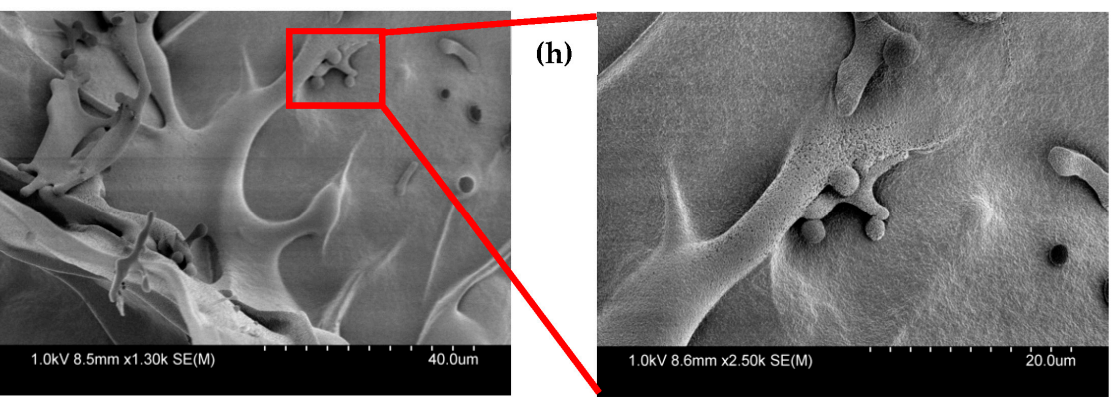

Figure 10. SEM images revealed morphological characteristics and interconnectivity of pores of bioprinted constructs. (a) Horizontal section of bioprinted constructs without microspheres. (b) Vertical section of bioprinted constructs without microspheres. (c) Horizontal section of bioprinted constructs with microspheres. (d) Vertical section of bioprinted constructs with microspheres. (e) At 100 um, horizontal section of bioprinted constructs showing microspheres are embedded in the bioprinted construct. (f) At 50 um, horizontal section of bioprinted constructs showing microspheres are embedded in the bioprinted construct. (g) At $40 \mathrm{um}$, vertical section of bioprinted constructs showing microspheres embedded in the bioprinted construct. (h) At 20 um, vertical section of bioprinted constructs showing microspheres embedded in the bioprinted construct. 


\subsection{Porosity of Bioprinted Constructs with and without Microspheres}

The bioprinted constructs with and without microspheres were lyophilized and the level of porosity measured. Figure 11 shows that the bioprinted constructs with microspheres and without microspheres had a porosity of $69.3 \% \pm 3.1$ and $66.1 \% \pm 3.2$, respectively. However, after performing a two-tailed Student's $t$-test, there was no significant difference between the two groups. As from Figure 6, SEM images also presented that microspheres were homogeneously distributed throughout the porous structures, without any large effect on porosity, likely due to their small size (1-10 um).

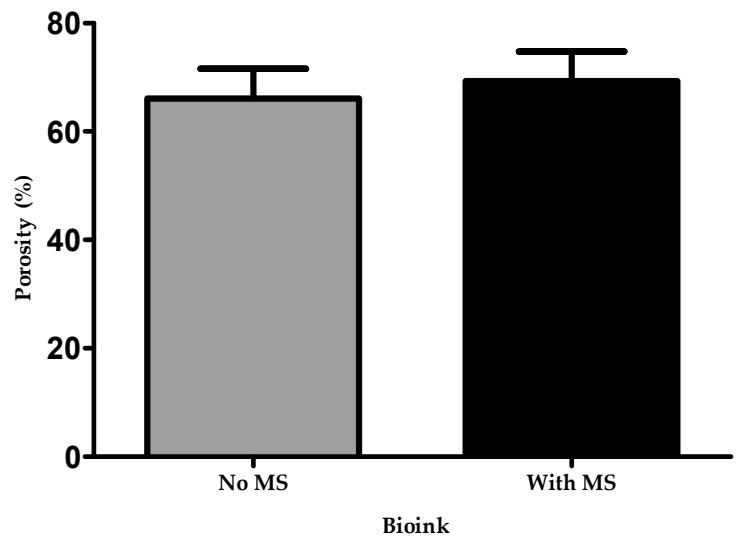

Figure 11. Porosity rate of bioprinted constructs with and without microspheres.

\subsection{Swelling Ratio of the Bioprinted Constructs with and without Microspheres}

An efficiently printed construct should swell after being placed in culture media and maintain its fluid in the 3D network. Mild swelling was observed in the constructs with and without microspheres after $24 \mathrm{~h}$ of incubation. Figure 12 shows the swelling ratio of bioprinted constructs with and without microspheres to be $24.3 \pm 0.1$ and $25.6 \pm 1.3$, respectively. There was no statistical difference between the two groups. Moreover, microspheres did not reduce water absorption, and both groups exhibited swelling without dissolving, which is critical for cell growth and differentiation.

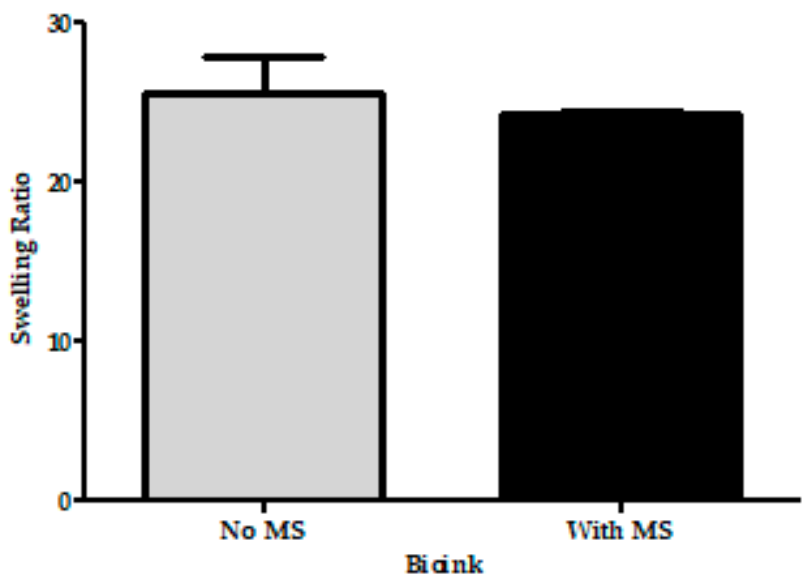

Figure 12. Swelling ratio of bioprinted construct with and without microspheres.

\subsection{Biodegradation of Bioprinted Constructs with and without Microspheres}

After culturing under standard conditions at $5 \% \mathrm{CO}_{2}$ and $37^{\circ} \mathrm{C}$ for 14 days, bioprinted constructs with cells and microspheres had the highest mechanical strength and lowest rate of degradation after 14 days. On the other hand, the bioprinted constructs containing microspheres but no cells had an intermediate mechanical strength and showed less degradation than the constructs with no microspheres or cells since they had a low mechanical 
strength and a maximum degradation. Figure 13 shows that there is a significant difference in all three groups, between microspheres and no microspheres, and between microspheres and microspheres and cells.

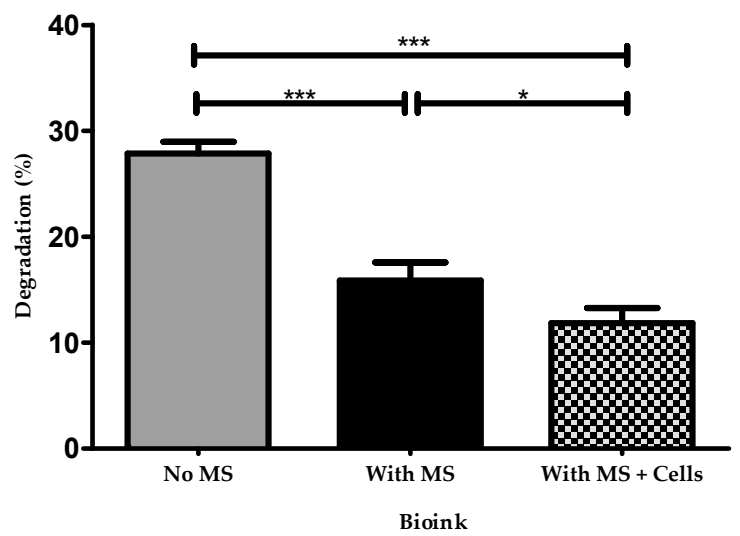

Figure 13. Biodegradation rate of bioprinted construct with cells and microspheres, with microspheres, and without microspheres. ${ }^{* * *}$ and ${ }^{*}$ indicates statistical differences between the three different groups.

\section{Discussion}

The differentiation of NPCs to mature phenotypes in bioprinted constructs depends on several factors, including the stiffness and porosity of the bioink that comprises the microenvironment. Our group has previously established that fibrin-based bioink printed with and without microspheres enables neuronal survival, proliferation, differentiation, and maturation $[59,60,62,68,70]$. In this study, we have determined the physicomechanical properties of bioprinted constructs as well as manually combined bioink and crosslink for tissue engineering applications.

In this study, dome-shaped structures were printed to analyze the microstructure, porosity, degradation, and elastic moduli using an indentation method. However, for the mechanical properties, due to the geometry of parallel plate on the rheometer, a uniform structure had to be used. Therefore, for these experiments, a disc-shaped structure was used instead of dome-shaped structure. To better understand our fibrin-based bioink, optimization and validation of several physical and mechanical properties were determined. Here, we analyzed the elastic moduli of the fibrin-based bioprinted constructs with and without microspheres. It was hypothesized that the elastic moduli of fibrin-based bioink that contained microspheres would be higher than the $30 \mathrm{mg} / \mathrm{mL}$ fibrin, which was previously evaluated by our group $[19,62]$. The elastic modulus was previously determined for fibrin-concentrations of 10,20 , and $30 \mathrm{mg} / \mathrm{mL}$ to be $262.7 \pm 5.7,590.9 \pm 23.5$, and $719.0 \pm 58.3 \mathrm{~Pa}$, respectively [19]. The indentation method used in this study combines spherical indenters and fluorescence microscopy, which allows the direct analysis of the elastic moduli of hydrogel samples. We determined the elastic moduli of bioprinted constructs with and without microspheres and found their moduli to be $1032 \pm 59.8$ and $728 \pm 47.6 \mathrm{~Pa}$, respectively. It was found that the constructs with microspheres were stiffer than the ones without microspheres. The Hertz theory displayed a high elastic modulus for a stiffer construct. These results showed that the incorporation of microspheres has a significant effect on stiffness, which can overcome the issue of faster degradation of bioprinted constructs; hence, stiffness will help in long-term culture and, ultimately, maturation of bioprinted neural tissues. Additionally, the elastic moduli of bioprinted constructs with microspheres was $\sim 1 \mathrm{kPa}$, which is similar to the optimal stiffness for neuronal differentiation shown in previous studies [64,78]. The elastic moduli values obtained by indentation corresponded to the values acquired by rheometry. In addition to the elastic moduli, the viscoelastic properties were determined, since extrusion through the bioprinter's nozzle depends on its viscosity. A useful printing solution should 
shear-thin under pressure, which implies that it should pass easily through the print nozzle and hold the printed shape once pressure is released [12]. If the viscosity is higher, then a higher pressure is required for extrusion [78]. High pressure creates high shear stress, which ultimately affects cell death. This facilitates the printing of high-fidelity structures; nevertheless, covalent crosslinking is required to attain a mechanically strong structure for long-term stability [3]. Our results showed that bioprinted constructs with and without microspheres, with cells and microspheres, and in a bioink and crosslinker solution exhibited shear-thinning behavior. Our bioink showed high viscosity at low applied shear stresses, exhibiting solid-like behavior. Moreover, the frequency sweep measurements showed that the $\mathrm{G}^{\prime}$ increased with higher concentrations of cells for bioprinted groups with microspheres, which indicates that bioprinted constructs store deformation energy in an elastic manner and make an increasingly stable structure with the addition of cells. $G^{\prime}$ exceeded $G^{\prime \prime}$ over the whole angular frequency range $\left(G^{\prime}>G^{\prime \prime}\right)$, and both moduli were dependent on frequency, which signified a standard gel structure under these conditions. In general, $G^{\prime}$ is more sensitive to any changes in the microstructure of viscoelastic systems in a frequency sweep test, and information about rigidity of samples can be obtained by $\mathrm{G}^{\prime}$.

Interestingly, several previous studies have discussed the effect of substrate elasticity on neural precursors $[19,35,64,69,77]$. Neurons have also shown sensitivity to rigidity. Neurites have been reported to grow faster on matrices from 0.1 to $1 \mathrm{kPa}$ compared to stiffer substrates [69]. Saha et al. validated that the hippocampus-derived NSC differentiation was favorable on softer substrates $(\mathrm{E}=0.1-0.5 \mathrm{kPa})$ compared to stiffer substrates $(\mathrm{E}=1-10 \mathrm{kPa})$ [36]. Moreover, Leipzig et al. demonstrated that forebrain-derived stem cells differentiated into mature neurons on substrates with a Young's modulus $<1 \mathrm{kPa}$; however, the proliferation of stem cells was ideal on $3.5 \mathrm{kPa}$ substrates ( $\mathrm{E}$ in the range of $<1-7 \mathrm{kPa}$ ) [64], and lastly, Previtera et al. validated that stiffer substrates facilitated the increase in branching relative to neurons grown on softer substrates at the same cell number [77]. Together, these studies showed that neuronal differentiation is optimal on $1 \mathrm{kPa}$ substrates, while stem cell proliferation is optimal on stiffer substrates $[19,35,64,69]$. Furthermore, the porosity of 3D-printed constructs plays a critical role in tissue engineering. A highly porous scaffold has large area for cell attachment and also enables the diffusion of nutrients and gases due to the removal of metabolic waste [57]. The incorporation of microspheres did not affect the porous structure of the bioprinted constructs. Bioprinted constructs with and without microspheres showed similar macroporous structures with interconnected pores and similar pore sizes between constructs with and without microspheres.

Swelling and degradation are relevant for bioprinted constructs, as these physical properties affect cell viability, proliferation, migration, and the creation of new tissue. The swelling properties can significantly affect the bioprinted tissue. Swelling means that the hydrogel does not dissolve in the solvent but rather increases in volume [53]. During our swelling studies, PBS was changed after $24 \mathrm{~h}$. As PBS was replaced, free chains were removed from the bioprinted samples, thereby reducing their swollen weights [52]. The swelling ratio of bioprinted constructs with and without microspheres was $24.3 \pm 0.1$ and $25.6 \pm 1.3$, respectively. Here, bioprinted constructs without microspheres showed similar swelling behavior as with microspheres due to the greater crosslinking. The observed swelling ratio was a balance between the uptake of water and the degradation rate of the constructs. Furthermore, the degradation time should match with the time required for desired tissue regeneration. Here, our bioprinted structure suffered the least amount of degradation when microspheres were incorporated into bioink. A significant difference was found among the groups. Thus, a controlled degradation rate is desired to achieve in tissue engineering. Here, degradation rate and mechanical properties can be tuned by incorporating microspheres, which have a greater influence on hydrogel degradation and swelling. Slow degradation kinetics is important to control the release of therapeutic molecules over a longer period of time [49]. These results showed that microspheres did not have a significant effect on the swelling and porosity of bioprinted constructs. However, our results showed that there is a possibility of specific physical interactions such 
as chemical bonding between the polymeric chains of biomaterials and microspheres. This results in an enhancement of the crosslinking density and, thus, in the increased strength and mechanical stability of the bioprinted constructs.

\section{Conclusions}

Here, we have demonstrated a set of methods for measuring the elastic moduli, viscoelasticity, and other physical properties of bioprinted constructs with and without microspheres. In general, the results showed our microsphere incorporated bioink behaved as a composite hydrogel, which could incorporate drugs to regulate cell fates, additional extracellular matrix elements to improve mechanical properties, and biomolecules to improve biological activities. In conclusion, the incorporation of microspheres in bioink enhanced the mechanical strength, lowered the degradation rate, and increased the elastic modulus of bioprinted tissues, thus making bioinks containing these particles highly suitable for neural tissue engineering applications.

Author Contributions: Conceptualization, R.S. and S.M.W.; Data curation, R.S., K.P.V. and R.K.; Formal analysis, R.S. and M.R.P.; Methodology, R.S. and K.P.V.; Investigation, R.S., R.K. and K.P.V.; Resources, S.M.W.; Supervision, S.M.W.; Validation, S.M.W.; Visualization, R.S.; Writing—original draft, R.S.; Writing —review and editing, R.K., M.R.P. and S.M.W. All authors have read and agreed to the published version of the manuscript.

Funding: Willerth receives funding from the NSERC Discovery Grant program, the Canada Research Chairs program, the Canadian Institutes of Health Research, the Alzheimer's Association, the Michael Smith Foundation for Health Research, and the Pacific Parkinson's Research Institute.

Institutional Review Board Statement: This study was conducted under the Biosafety and Human Ethics approval at the University of Victoria.

Informed Consent Statement: Not applicable.

Data Availability Statement: Data available upon request.

Acknowledgments: We thank Kali Schek and Claire Benwood for their support with preparation of bioink and 3D bioprinting as well as Christine Wong Chong and Meghan Robinson for analyzing graphs and reviewing the manuscript.

Conflicts of Interest: Willerth is the CEO and co-founder of Axolotl Biosciences, a start-up that sells novel bioinks.

\section{References}

1. Thomas, M.; Willerth, S.M. 3-D Bioprinting of Neural Tissue for Applications in Cell Therapy and Drug Screening. Front. Bioeng. Biotechnol. 2017, 5, 69. [CrossRef] [PubMed]

2. Mazzocchi, A.; Soker, S.; Skardal, A. 3D bioprinting for high-throughput screening: Drug screening, disease modeling, and precision medicine applications. Appl. Phys. Rev. 2019, 6. [CrossRef] [PubMed]

3. Hu, T.; Cui, X.; Zhu, M.; Wu, M.; Tian, Y.; Yao, B.; Song, W.; Niu, Z.; Huang, S.; Fu, X. 3D-printable supramolecular hydrogels with shear-thinning property: Fabricating strength tunable bioink via dual crosslinking. Bioact. Mater. 2020, 5, 808-818. [CrossRef]

4. Kiyotake, E.A.; Douglas, A.W.; Thomas, E.E.; Nimmo, S.L.; Detamore, M.S. Development and quantitative characterization of the precursor rheology of hyaluronic acid hydrogels for bioprinting. Acta Biomater. 2019, 95, 176-187. [CrossRef]

5. Seidlits, S.K.; Khaing, Z.Z.; Petersen, R.R.; Nickels, J.D.; Vanscoy, J.E.; Shear, J.B.; Schmidt, C.E. The effects of hyaluronic acid hydrogels with tunable mechanical properties on neural progenitor cell differentiation. Biomaterials 2010, 31, 3930-3940. [CrossRef]

6. Ouyang, L.; Yao, R.; Zhao, Y.; Sun, W. Effect of bioink properties on printability and cell viability for 3D bioplotting of embryonic stem cells. Biofabrication 2016, 8, 035020. [CrossRef] [PubMed]

7. Parak, A.; Pradeep, P.; du Toit, L.C.; Kumar, P.; Choonara, Y.E.; Pillay, V. Functionalizing bioinks for 3D bioprinting applications. Drug Discov. Today 2019, 24, 198-205. [CrossRef]

8. Benwood, C.; Chrenek, J.; Kirsch, R.L.; Masri, N.Z.; Richards, H.; Teetzen, K.; Willerth, S.M. Natural Biomaterials and Their Use as Bioinks for Printing Tissues. Bioengineering 2021, 8, 27. [CrossRef]

9. Yu, C.; Zhu, W.; Sun, B.; Mei, D.; Gou, M.; Chen, S. Modulating physical, chemical, and biological properties in 3D printing for tissue engineering applications. Appl. Phys. Rev. 2018, 5. [CrossRef] 
10. Cooke, M.E.; Rosenzweig, D.H. The rheology of direct and suspended extrusion bioprinting. APL Bioeng. 2021, 5, 011502. [CrossRef]

11. Diamantides, N.; Wang, L.; Pruiksma, T.; Siemiatkoski, J.; Dugopolski, C.; Shortkroff, S.; Kennedy, S.; Bonassar, L.J. Correlating rheological properties and printability of collagen bioinks: The effects of riboflavin photocrosslinking and pH. Biofabrication 2017, 9, 034102. [CrossRef] [PubMed]

12. Cheng, S.; Clarke, E.C.; Bilston, L.E. Rheological properties of the tissues of the central nervous system: A review. Med. Eng. Phys. 2008, 30, 1318-1337. [CrossRef]

13. Chopin-Doroteo, M.; Mandujano-Tinoco, E.A.; Krotzsch, E. Tailoring of the rheological properties of bioinks to improve bioprinting and bioassembly for tissue replacement. Biochim. Biophys. Acta Gen. Subj. 2021, 1865, 129782. [CrossRef]

14. Paxton, N.; Smolan, W.; Bock, T.; Melchels, F.; Groll, J.; Jungst, T. Proposal to assess printability of bioinks for extrusion-based bioprinting and evaluation of rheological properties governing bioprintability. Biofabrication 2017, 9, 044107. [CrossRef]

15. Lee, J.; Oh, S.J.; An, S.H.; Kim, W.D.; Kim, S.H. Machine learning-based design strategy for 3D printable bioink: Elastic modulus and yield stress determine printability. Biofabrication 2020, 12, 035018. [CrossRef]

16. Ahmed, E.M. Hydrogel: Preparation, characterization, and applications: A review. J. Adv. Res. 2015, 6, 105-121. [CrossRef] [PubMed]

17. Moeinzadeh, S.; Jabbari, E. Gelation characteristics, physico-mechanical properties and degradation kinetics of micellar hydrogels. Eur. Polym. J. 2015, 72, 566-576. [CrossRef] [PubMed]

18. Zhao, Z.; Vizetto-Duarte, C.; Moay, Z.K.; Setyawati, M.I.; Rakshit, M.; Kathawala, M.H.; Ng, K.W. Composite Hydrogels in Three-Dimensional in vitro Models. Front. Bioeng. Biotechnol. 2020, 8, 611. [CrossRef] [PubMed]

19. Robinson, M.; Valente, K.P.; Willerth, S.M. A Novel Toolkit for Characterizing the Mechanical and Electrical Properties of Engineered Neural Tissues. Biosensors 2019, 9, 51. [CrossRef] [PubMed]

20. Kayal, C.; Moeendarbary, E.; Shipley, R.J.; Phillips, J.B. Mechanical Response of Neural Cells to Physiologically Relevant Stiffness Gradients. Adv. Healthc. Mater. 2020, 9, e1901036. [CrossRef]

21. Canovic, E.P.; Qing, B.; Mijailovic, A.S.; Jagielska, A.; Whitfield, M.J.; Kelly, E.; Turner, D.; Sahin, M.; Van Vliet, K.J. Characterizing Multiscale Mechanical Properties of Brain Tissue Using Atomic Force Microscopy, Impact Indentation, and Rheometry. J. Vis. Exp. 2016. [CrossRef]

22. Aurand, E.R.; Lampe, K.J.; Bjugstad, K.B. Defining and designing polymers and hydrogels for neural tissue engineering. Neurosci. Res. 2012, 72, 199-213. [CrossRef] [PubMed]

23. MacManus, D.B.; Pierrat, B.; Murphy, J.G.; Gilchrist, M.D. Dynamic mechanical properties of murine brain tissue using microindentation. J. Biomech. 2015, 48, 3213-3218. [CrossRef]

24. Budday, S.; Sommer, G.; Birkl, C.; Langkammer, C.; Haybaeck, J.; Kohnert, J.; Bauer, M.; Paulsen, F.; Steinmann, P.; Kuhl, E.; et al. Mechanical characterization of human brain tissue. Acta Biomater. 2017, 48, 319-340. [CrossRef]

25. Rashid, B.; Destrade, M.; Gilchrist, M.D. Mechanical characterization of brain tissue in simple shear at dynamic strain rates. $J$. Mech. Behav. Biomed. Mater. 2013, 28, 71-85. [CrossRef]

26. Lee, S.J.; King, M.A.; Sun, J.; Xie, H.K.; Subhash, G.; Sarntinoranont, M. Measurement of viscoelastic properties in multiple anatomical regions of acute rat brain tissue slices. J. Mech. Behav. Biomed. Mater. 2014, 29, 213-224. [CrossRef]

27. Chatelin, S.; Constantinesco, A.; Willinger, R. Fifty years of brain tissue mechanical testing: From in vitro to in vivo investigations. Biorheology 2010, 47, 255-276. [CrossRef]

28. Kim, H.N.; Choi, N. Consideration of the Mechanical Properties of Hydrogels for Brain Tissue Engineering and Brain-on-a-chip. BioChip J. 2019, 13, 8-19. [CrossRef]

29. van Dommelen, J.A.; van der Sande, T.P.; Hrapko, M.; Peters, G.W. Mechanical properties of brain tissue by indentation: Interregional variation. J. Mech. Behav. Biomed. Mater. 2010, 3, 158-166. [CrossRef]

30. Budday, S.; Nay, R.; de Rooij, R.; Steinmann, P.; Wyrobek, T.; Ovaert, T.C.; Kuhl, E. Mechanical properties of gray and white matter brain tissue by indentation. J. Mech. Behav. Biomed. Mater. 2015, 46, 318-330. [CrossRef]

31. Lee, D.; Rahman, M.M.; Zhou, Y.; Ryu, S. Three-Dimensional Confocal Microscopy Indentation Method for Hydrogel Elasticity Measurement. Langmuir 2015, 31, 9684-9693. [CrossRef]

32. Long, R.; Hall, M.S.; Wu, M.; Hui, C.Y. Effects of gel thickness on microscopic indentation measurements of gel modulus. Biophys. J. 2011, 101, 643-650. [CrossRef] [PubMed]

33. Prevost, T.P.; Jin, G.; de Moya, M.A.; Alam, H.B.; Suresh, S.; Socrate, S. Dynamic mechanical response of brain tissue in indentation in vivo, in situ and in vitro. Acta Biomater. 2011, 7, 4090-4101. [CrossRef]

34. Engler, A.J.; Sen, S.; Sweeney, H.L.; Discher, D.E. Matrix elasticity directs stem cell lineage specification. Cell 2006, 126, 677-689. [CrossRef]

35. Her, G.J.; Wu, H.C.; Chen, M.H.; Chen, M.Y.; Chang, S.C.; Wang, T.W. Control of three-dimensional substrate stiffness to manipulate mesenchymal stem cell fate toward neuronal or glial lineages. Acta Biomater. 2013, 9, 5170-5180. [CrossRef] [PubMed]

36. Saha, K.; Keung, A.J.; Irwin, E.F.; Li, Y.; Little, L.; Schaffer, D.V.; Healy, K.E. Substrate modulus directs neural stem cell behavior. Biophys. J. 2008, 95, 4426-4438. [CrossRef]

37. Sundararaghavan, H.G.; Monteiro, G.A.; Firestein, B.L.; Shreiber, D.I. Neurite growth in 3D collagen gels with gradients of mechanical properties. Biotechnol. Bioeng. 2009, 102, 632-643. [CrossRef] 
38. Freeman, F.E.; Kelly, D.J. Tuning Alginate Bioink Stiffness and Composition for Controlled Growth Factor Delivery and to Spatially Direct MSC Fate within Bioprinted Tissues. Sci. Rep. 2017, 7, 17042. [CrossRef]

39. Diamantides, N.; Dugopolski, C.; Blahut, E.; Kennedy, S.; Bonassar, L.J. High density cell seeding affects the rheology and printability of collagen bioinks. Biofabrication 2019, 11, 045016. [CrossRef]

40. Schwab, A.; Levato, R.; D’Este, M.; Piluso, S.; Eglin, D.; Malda, J. Printability and Shape Fidelity of Bioinks in 3D Bioprinting. Chem. Rev. 2020, 120, 11028-11055. [CrossRef]

41. Zhao, Y.; Li, Y.; Mao, S.; Sun, W.; Yao, R. The influence of printing parameters on cell survival rate and printability in microextrusion-based 3D cell printing technology. Biofabrication 2015, 7, 045002. [CrossRef]

42. Hospodiuk, M.; Dey, M.; Sosnoski, D.; Ozbolat, I.T. The bioink: A comprehensive review on bioprintable materials. Biotechnol. Adv. 2017, 35, 217-239. [CrossRef]

43. Li, Z.; Ji, C.; Li, D.; Luo, R.; Wang, G.; Jiang, J. A comprehensive study on the mechanical properties of different regions of 8-week-old pediatric porcine brain under tension, shear, and compression at various strain rates. J. Biomech. 2020, 98, 109380. [CrossRef] [PubMed]

44. Cadena, M.; Ning, L.; King, A.; Hwang, B.; Jin, L.; Serpooshan, V.; Sloan, S.A. 3D Bioprinting of Neural Tissues. Adv. Healthc. Mater. 2020, e2001600. [CrossRef]

45. Zhang, S.; Li, G.; Man, J.; Zhang, S.; Li, J.; Li, J.; Li, D. Fabrication of Microspheres from High-Viscosity Bioink Using a Novel Microfluidic-Based 3D Bioprinting Nozzle. Micromachines 2020, 11, 681. [CrossRef]

46. Heid, S.; Boccaccini, A.R. Advancing bioinks for 3D bioprinting using reactive fillers: A review. Acta Biomater. 2020, 113, 1-22. [CrossRef]

47. Chimene, D.; Lennox, K.K.; Kaunas, R.R.; Gaharwar, A.K. Advanced Bioinks for 3D Printing: A Materials Science Perspective. Ann. Biomed. Eng. 2016, 44, 2090-2102. [CrossRef]

48. Rizwan, M.; Chan, S.W.; Comeau, P.A.; Willett, T.L.; Yim, E.K.F. Effect of sterilization treatment on mechanical properties, biodegradation, bioactivity and printability of GelMA hydrogels. Biomed. Mater. 2020, 15, 065017. [CrossRef]

49. Wu, Z.; Su, X.; Xu, Y.; Kong, B.; Sun, W.; Mi, S. Bioprinting three-dimensional cell-laden tissue constructs with controllable degradation. Sci. Rep. 2016, 6, 24474. [CrossRef]

50. Wei, L.; Li, Z.; Li, J.; Zhang, Y.; Yao, B.; Liu, Y.; Song, W.; Fu, X.; Wu, X.; Huang, S. An approach for mechanical property optimization of cell-laden alginate-gelatin composite bioink with bioactive glass nanoparticles. J. Mater. Sci. Mater. Med. 2020, 31, 103. [CrossRef] [PubMed]

51. Mao, Q.; Wang, Y.; Li, Y.; Juengpanich, S.; Li, W.; Chen, M.; Yin, J.; Fu, J.; Cai, X. Fabrication of liver microtissue with liver decellularized extracellular matrix (dECM) bioink by digital light processing (DLP) bioprinting. Mater. Sci. Eng. C Mater. Biol. Appl. 2020, 109, 110625. [CrossRef]

52. Liu, W.; Borrell, M.A.; Venerus, D.C.; Mieler, W.F.; Kang-Mieler, J.J. Characterization of Biodegradable Microsphere-Hydrogel Ocular Drug Delivery System for Controlled and Extended Release of Ranibizumab. Transl. Vis. Sci. Technol. 2019, 8, 12 [CrossRef] [PubMed]

53. Li, Z.; Huang, S.; Liu, Y.; Yao, B.; Hu, T.; Shi, H.; Xie, J.; Fu, X. Tuning Alginate-Gelatin Bioink Properties by Varying Solvent and Their Impact on Stem Cell Behavior. Sci. Rep. 2018, 8, 8020. [CrossRef] [PubMed]

54. Noh, I.; Kim, N.; Tran, H.N.; Lee, J.; Lee, C. 3D printable hyaluronic acid-based hydrogel for its potential application as a bioink in tissue engineering. Biomater. Res. 2019, 23, 3. [CrossRef]

55. Daikuara, L.Y.; Yue, Z.; Skropeta, D.; Wallace, G.G. In vitro characterisation of 3D printed platelet lysate-based bioink for potential application in skin tissue engineering. Acta Biomater. 2021, 123, 286-297. [CrossRef] [PubMed]

56. Kim, B.S.; Das, S.; Jang, J.; Cho, D.W. Decellularized Extracellular Matrix-based Bioinks for Engineering Tissue- and Organ-specific Microenvironments. Chem. Rev. 2020, 120, 10608-10661. [CrossRef]

57. Mansouri, N.; Al-Sarawi, S.F.; Mazumdar, J.; Losic, D. Advancing fabrication and properties of three-dimensional graphenealginate scaffolds for application in neural tissue engineering. RSC Adv. 2019, 9, 36838-36848. [CrossRef]

58. Zhang, T.; Yan, K.C.; Ouyang, L.; Sun, W. Mechanical characterization of bioprinted in vitro soft tissue models. Biofabrication 2013, 5, 045010. [CrossRef]

59. De la Vega, L.; Abelseth, L.; Sharma, R.; Triviño-Paredes, J.; Restan, M.; Willerth, S.M. 3D Bioprinting Human-Induced Pluripotent Stem Cells and Drug-Releasing Microspheres to Produce Responsive Neural Tissues. Adv. NanoBiomed Res. 2021. [CrossRef]

60. Sharma, R.; Smits, I.P.M.; De La Vega, L.; Lee, C.; Willerth, S.M. 3D Bioprinting Pluripotent Stem Cell Derived Neural Tissues Using a Novel Fibrin Bioink Containing Drug Releasing Microspheres. Front. Bioeng. Biotechnol. 2020, 8, 57. [CrossRef]

61. Cota-Coronado, A.; Durnall, J.C.; Diaz, N.F.; Thompson, L.H.; Diaz-Martinez, N.E. Unprecedented Potential for Neural Drug Discovery Based on Self-Organizing hiPSC Platforms. Molecules 2020, 25, 1150. [CrossRef] [PubMed]

62. Abelseth, E.; Abelseth, L.; De la Vega, L.; Beyer, S.T.; Wadsworth, S.J.; Willerth, S.M. 3D Printing of Neural Tissues Derived from Human Induced Pluripotent Stem Cells Using a Fibrin-Based Bioink. ACS Biomater. Sci. Eng. 2019, 5, 234-243. [CrossRef] [PubMed]

63. de Melo, B.A.G.; Jodat, Y.A.; Cruz, E.M.; Benincasa, J.C.; Shin, S.R.; Porcionatto, M.A. Strategies to use fibrinogen as bioink for 3D bioprinting fibrin-based soft and hard tissues. Acta Biomater. 2020, 117, 60-76. [CrossRef] [PubMed]

64. Leipzig, N.D.; Shoichet, M.S. The effect of substrate stiffness on adult neural stem cell behavior. Biomaterials 2009, 30, 6867-6878. [CrossRef] 
65. Peak, C.W.; Singh, K.A.; Adlouni, M.A.; Chen, J.; Gaharwar, A.K. Printing Therapeutic Proteins in 3D using Nanoengineered Bioink to Control and Direct Cell Migration. Adv. Healthc. Mater. 2019, 8. [CrossRef] [PubMed]

66. Yan, C.; Pochan, D.J. Rheological properties of peptide-based hydrogels for biomedical and other applications. Chem. Soc. Rev. 2010, 39, 3528-3540. [CrossRef]

67. Karoyo, A.H.; Wilson, L.D. Physicochemical Properties and the Gelation Process of Supramolecular Hydrogels: A Review. Gels 2017, 3, 1. [CrossRef]

68. Agbay, A.; De La Vega, L.; Nixon, G.; Willerth, S. Guggulsterone-releasing microspheres direct the differentiation of human induced pluripotent stem cells into neural phenotypes. Biomed. Mater. 2018, 13. [CrossRef]

69. Previtera, M.L.; Langhammer, C.G.; Firestein, B.L. Effects of substrate stiffness and cell density on primary hippocampal cultures J. Biosci. Bioeng. 2010, 110, 459-470. [CrossRef]

70. de la Vega, L.; A Rosas Gómez, D.; Abelseth, E.; Abelseth, L.; Allisson da Silva, V.; Willerth, S. 3D Bioprinting Human Induced Pluripotent Stem Cell-Derived Neural Tissues Using a Novel Lab-on-a-Printer Technology. Appl. Sci. 2018, 8, 2414. [CrossRef]

71. Gross, W.; Kress, H. Simultaneous measurement of the Young's modulus and the Poisson ratio of thin elastic layers. Soft Matter 2017, 13, 1048-1055. [CrossRef]

72. Valente, K.P.; Thind, S.S.; Akbari, M.; Suleman, A.; Brolo, A.G. Collagen Type I-Gelatin Methacryloyl Composites: Mimicking the Tumor Microenvironment. ACS Biomater. Sci. Eng. 2019, 5, 2887-2898. [CrossRef]

73. Galluzzi, M.; Biswas, C.S.; Wu, Y.; Wang, Q.; Du, B.; Stadler, F.J. Space-resolved quantitative mechanical measurements of soft and supersoft materials by atomic force microscopy. NPG Asia Mater. 2016, 8, e327. [CrossRef]

74. Rutz, A.L.; Gargus, E.S.; Hyland, K.E.; Lewis, P.L.; Setty, A.; Burghardt, W.R.; Shah, R.N. Employing PEG crosslinkers to optimize cell viability in gel phase bioinks and tailor post printing mechanical properties. Acta Biomater. 2019, 99, 121-132. [CrossRef] [PubMed]

75. Bociaga, D.; Bartniak, M.; Grabarczyk, J.; Przybyszewska, K. Sodium Alginate/Gelatine Hydrogels for Direct Bioprinting-The Effect of Composition Selection and Applied Solvents on the Bioink Properties. Materials 2019, 12, 2669. [CrossRef]

76. Lopez-Guerra, E.A.; Solares, S.D. On the frequency dependence of viscoelastic material characterization with intermittent-contact dynamic atomic force microscopy: Avoiding mischaracterization across large frequency ranges. Beilstein. J. Nanotechnol. 2020, 11, 1409-1418. [CrossRef]

77. Previtera, M.L.; Hui, M.; Verma, D.; Shahin, A.J.; Schloss, R.; Langrana, N.A. The effects of substrate elastic modulus on neural precursor cell behavior. Ann. Biomed. Eng. 2013, 41, 1193-1207. [CrossRef]

78. Budday, S.; Sommer, G.; Holzapfel, G.A.; Steinmann, P.; Kuhl, E. Viscoelastic parameter identification of human brain tissue. J. Mech. Behav. Biomed. Mater. 2017, 74, 463-476. [CrossRef] 